DOE DE-FC26-98T40447

FINAL REPORT

July 2002

\title{
PARTICLE TRANSPORTATION AND DEPOSITION \\ IN HOT GAS FILTER VESSELS -A \\ COMPUTATIONAL AND EXPERIMENTAL \\ MODELING APPROACH
}

Grant Number: DE-FC26-98T40447

Goodarz Ahmadi

Department of Mechanical and Aeronautical Engineering

Clarkson University

Submitted to

U.S. Department of Energy

National Energy Technology Laboratory 


\section{DISCLAIMER}

This report was prepared as an account of work sponsored by an agency of the United States Government. Neither the United States Government nor any agency thereof, nor any of their employees, makes any warranty, express or implied, or assumes any legal liability or responsibility for the accuracy, completeness, or usefulness of any information, apparatus, product, or process disclosed, or represents that its use would not infringe privately owned rights. Reference herein to any specific commercial product, process, or service by trade name, trademark, manufacturer, or otherwise does not necessarily constitute or imply its endorsement, recommendation or favoring by the United States Government nor any agency thereof. The views and opinions of authors expressed herein do not necessarily state or reflect those of the United States Government nor any agency thereof. 
Table of Contents

Page

DISCLAIMER

SUMMARY

SCOPE OF WORK

SUMMARY OF PROJECT TASKS

HOT-GAS FLOW AND PARTICLE TRANSPORT

AND DEPOSITION IN THE SIEMENS-

WESTINGHOUSE FILTER VESSEL

HOT-GAS FLOW AND PARTICLE TRANSPORT

AND DEPOSITION IN THE SIEMENS-WESTINGHOUSE

FILTER VESSEL - ALTERNATE DESIGNS

EXPERIMENTAL STUDY

TEMPERATURE DISTRIBUTION IN SIEMENS-WESTINGHOUSE

FILTER VESSEL WITH ASH BRIDGING

STUDENTS AND COLLABORATORS 
TITLE:

\section{PARTICLE TRANSPORTATION AND DEPOSITION IN HOT GAS FILTER VESSELS -A COMPUTATIONAL AND EXPERIMENTAL MODELING APPROACH}

PI

Goodarz Ahmadi

STUDENTS: $\quad$ C. He, H. Zhang, A. R. Mazaheri, C. Liu, P. Zamankhan

INSTITUTION: Clarkson University

Potsdam, NY 13699-5725

Tel: (315) 268-2322

Fax: (315) 268-6438

Email: ahmadi@clarkson.edu

GRANT NO.: $\quad$ DE-FC26-98T40447

PERIOD OF

PERFORMANCE: September 1, 1998 to June 30, 2002

DOE Project Officer: Dr. Theodore McMahon

\section{SUMMARY}

In this project, a computational modeling approach for analyzing flow and ash transport and deposition in filter vessels was developed. An Eulerian-Largrangian formulation for studying hot-gas filtration process was established. The approach uses an Eulerian analysis of gas flows in the filter vessel, and makes use of the Lagrangian trajectory analysis for the particle transport and deposition. Particular attention was given to the Siemens-Westinghouse filter vessel at Power System Development Facility in Wilsonville in Alabama. Details of hot-gas flow in this tangential flow filter vessel are evaluated. The simulation results show that the rapidly rotation flow in the spacing between the shroud and the vessel refractory acts as cyclone that leads to the removal of a large fraction of the larger particles from the gas stream.

Several alternate designs for the filter vessel are considered. These include a vessel with a short shroud, a filter vessel with no shroud and a vessel with a deflector plate. The hot-gas flow and particle transport and deposition in various vessels are evaluated. The deposition patterns in various vessels are compared. It is shown that certain filter vessel designs allow for the large particles to remain suspended in 
the gas stream and to deposit on the filters. The presence of the larger particles in the filter cake leads to lower mechanical strength thus allowing for the back-pulse process to more easily remove the filter cake.

A laboratory-scale filter vessel for testing the cold flow condition was designed and fabricated. A laser-based flow visualization technique is used and the gas flow condition in the laboratory-scale vessel was experimental studied. A computer model for the experimental vessel was also developed and the gas flow and particle transport patterns are evaluated.

\section{SCOPE OF WORK}

The main objective of this project is to provide a fundamental understanding of transport and deposition of particles in hot-gas cleanup filter vessels. The general goal is to develop the needed tools for optimal design of hot-gas filtration systems to avoid filter-ash bridging. The specific objectives are:

i) To provide a fundamental understanding of particle transport and deposition mechanisms, in hotgas cleanup filter vessels.

ii) To provide a comprehensive set of experimental data for the details of the gas flow and particle transport in a laboratory-scale filtration system.

iii) To develop a scientific basis for the mechanisms for ash bridging in hot-gas filtration systems. This will be accomplished through a comprehensive set of laboratory-scale experiments in addition to extensive computer modeling.

iv) To provide extensive set of computer simulations for pilot- and demonstration-scale hot gas filter systems

v) To develop guidelines for performance improvement of hot-gas filter systems and for avoiding ash bridging.

\section{SUMMARY OF PROJECT TASKS}

\section{Task 1 - Upgrade of Computational Model for Ash Transport and Deposition}

This task upgraded the computational model for transport and deposition of ash particles in the hot-gas cleanup filter vessels and included all the relevant forces. For submicron particles, the Brownian diffusion effect was included in the model.

\section{Task 2 - Simulation of Ash Transport and Deposition in Filter Vessels}


This task performed a number of digital simulations for transport and deposition of ash particles in different hot-gas cleanup filter vessels. Various particle sizes in the range of 0.1 to $30 \mathrm{~m}$ was used in the simulation, and the effects of variations in density ratio, turbulence intensity, thermal condition, and geometric feature of the filter vessel were studied. Uniform inlet concentrations, as well as different sources of particle were used in these simulations.

\section{Task 3 - Experimental Study of Gas Flows in Laboratory-Scale Filter Vessel}

This task performed an experimental study of the gas flow pattern in the laboratory-scale filter vessel. A flow visualization technique was used. Uniform inlet concentration of glycerin droplet was used in the flow visualization study. The experimentation was under cold flow conditions.

\section{Task 4 - Filter-Ash Bridging}

This task simulated the hot-gas flow and particle transport near solid surfaces in the filter vessel. The goal was to provide insight into the potential for ash bridging under various conditions. Particular attention was given to understanding the fundamental physics of the process. The importance of deposition on solid surfaces in initiating ash bridging was pointed out.

\section{Task 5.0 - Design Guideline}

This task provided design guideline for reducing the potential for ash bridging in the hot-gas filtration systems. This was done through a series of computer simulations and studying the effects of design alterations for the Particle Control Device (PCD) at Power System Development Facilities (PSDF) at Wilsonville, AL.

\section{Task 6.0 - Simulation of Filter System Back-Pulse Cleaning}

This task simulated the (fast transient) pulse-jet reverse flow pattern in a filter vessel, and assessed its effectiveness for the filter cake removal. The effect of gas compressibility and rapid change in pressure and temperature was included. The details of the gas flow inside the candle filters were analyzed, and the efficiency of the cake cleaning process examined.

\section{Scope of Additional Work for 2001}

In the latter part of 2000 the projected was amended for performing additional work. Earlier study showed that the tangential inlet on the Siemens Westinghouse filter vessel at the Power System Development Facility (PSDF) resulted in a highly swirling flow in the vessel. The cyclonic nature of this flow led to the separation of larger particles (of the order of 30 microns or larger). These relatively large particles either deposited on the non-filtering surfaces (mainly in the shroud) or dropped directly to the bottom of the vessel. This was an undesirable situation. Exclusion of larger particles resulted in filter cakes 
of low permeability and high strength. Also, in many situations it was desirable to add particulate matter to the gas stream as sorbent or filter cake conditioner up stream of the filter vessel. But because these additional particulate matters with effective diameters larger than (30 microns) never reached the filter cake, it was suggested to evaluate the redesign the filter vessel such that all particles entering the vessel inlet could reach the filter cake.

\section{Additional Tasks Performed in 2001-2002}

The plan was to introduce design modifications for the Siemens Westinghouse filter vessel at the PSDF to ensure that particles of all sizes entering the filter vessel reach the candle filter elements. The tasks listed below were expanded form of Task 5.0 ADesign Guideline@f the Statement of Work of the original project.

\section{Task 5 - Design Guideline}

This task provided design guideline for reducing the potential for ash bridging in the hot-gas filtration systems. This was to be done through a series of computer simulations and studying the effects of design alterations.

\section{Task 5.1 - Design modifications}

This task developed design modifications for the Siemens-Westinghouse filter vessel at the PSDF in order to reduce the particle separation due the cyclonic actions. The following options were examined.

- Filter Vessel with Partially Blocked Shroud

- Filter Vessel with a Mini-Shroud

- Filter Vessel with no Shroud

- Filter Vessel with a Deflector Vane

\section{Task 5.2 - Up Grade of Computational Model}

This task performed an important upgrade of the computational model for the hot-gas flow and transport and deposition of ash particles in the Siemens Westinghouse filter vessels. The earlier developed model used six effective filters for the upper tier and one large effective filter for the lower tier. The upgraded computational model used seven effective filters for the lower tier and more accurately represented the hot-gas flow and particle transport paterns in the vessel.

\section{Task 5.3 - Gas Flow and Ash Transport and Deposition in Siemens-Westinghouse Filter Vessel with Modified Design}


This performed a number of computer simulations for gas flow and ash transport and deposition in the Siemens Westinghouse filter vessels at PSDF with different design modifications. Various particle sizes were used in these simulations, and the effects of design modifications on the reduction of the cyclonic action in the vessel were studied. The study provided different options for design modifications of the Siemens-Westinghouse filter vessel to be implemented at the PSDF. The specific cases studied were:

\section{Sub-Task 5.3.1 - Filter Vessel with Partially Blocked Shroud \\ Sub-Task 5.3.2 - Filter Vessel with a Mini-Shroud \\ Sub-Task 5.3.3 - Filter Vessel with no Shroud \\ Sub-Task 5.3.4 - Filter Vessel with a Deflector Vane}

\section{Task 5.4 - Final Report Preparation}

This task prepared the final report. 


\section{TECHNICAL REPORT}

\section{GENERAL}

All tasks of the research project were completed. The description of the technical findings concerning the hot-gas flow and ash transport in the Siemens-Westinghouse filter vessel and its alternate designs are presented. This is followed by a discussion of the experimental study. One important additional accomplishment of the project is the computer simulation of the temperature variation in the filter vessel with without the presence of ash bridging. This additional effort was undertaken to provide additional important information for the operation of the filter vessel.

\section{HOT-GAS FLOW AND PARTICLE TRANSPORT AND DEPOSITION IN THE SIEMENS- WESTINGHOUSE FILTER VESSEL}

In this section, hot-gas flow and particle transport and deposition in the Siemens-Westinghouse filter vessel at Power System Development Facility in Wilsonville in Alabama are studied. This tangential flow filter vessel contains clusters of 91 candle filters, which are arranged in two tiers. The upper tier that contains 36 candle filters is modeled by six equivalent filters. Seven equivalent filters are used in the computational model to represent the 55 candle filters in the lower tiers. The Reynolds stress turbulent model of FLUENT ${ }^{\mathrm{TM}}$ code is used and the gas mean velocity and root mean square fluctuation velocities in the filter vessel are evaluated. The particle equation of motion used includes drag and gravitational forces. The mean particle deposition patterns are evaluated and the effect of particle size is studied. The computational results indicates that the large particles of the order of $10 \mu \mathrm{m}$ or larger are removed from the gas due to the centrifugal forces exerted by rotating flow between the shroud and the refractory.

\section{Introduction}

Developing advanced clean coal technology for electric power generation with high efficiency and low pollutants has seen considerable interest in the recent years. As a result, the advanced pressurized fluidized bed combustion (PFBC) and integrated gasification combined cycles (IGCC) are developed and are being tested as part of the Clean Coal Technology Program of the US Department of Energy. These highly efficient advanced coal energy systems require effective removal of ash and unreacted and reacted sulfur sorbent from the hot gases.

The procedure for cleaning hot gases has been focused on the use of ceramic candle filters. In practice, an industrial filter vessel contains a several hundred candle filters. Dust cake builds up on the filters during the operation of the system. Groups of candle filters are periodically cleaned by a back pulse procedure. In the past decade, a number of pilot and demonstration scale hot-gas filtration systems were developed and tested. 
In this work, particle transport and deposition in a tangential flow hot-gas filtration device is studied. Particular attention is given to the Siemens-Westinghouse Particulate Control Device (PCD) at the demonstration-scale Power System Development Facility in Wilsonville, Alabama. To be able to assess the effect of strong tangential flow in the vessel on deposition pattern of different size particles, a refined grid was generated and used in the analysis. The Reynolds stress turbulence model of the FLUENT ${ }^{\mathrm{TM}}$ code is used for evaluating the gas mean velocity and the root mean-square fluctuation velocity in the filter vessel. The deposition patterns of ash particles of different sizes are evaluated. The particle equation of motion including the drag and the gravitational forces are used in the simulation. The results show that the centrifugal forces generated by the rotational motion significantly affect the transport and deposition of large particles. In particular, a large fraction of $10 \mu \mathrm{m}$ particles (or larger) deposit in the region between the shroud and the vessel refractory.

\section{Hot-Gas Filter Vessel}

The special case studied is that of the Siemens-Westinghouse tangential flow hot-gas filter vessel that is currently being tested at the Southern Research Company Facility (PSDF) at Wilsonville near Birmingham, Alabama. This Particle Control Device (PCD) is $1.6 \mathrm{~m}$ (63 in) in diameter and $8.27 \mathrm{~m}$ (325.7 in) long. The vessel accommodates 91 candle filters arranged in two clusters. The upper and lower tiers have, respectively, 36 and 55 candle filters. The ceramic candle filters are about $6 \mathrm{~cm}$ (2.36 in) in outer diameter and 1.5m (4.92 ft) long. A special feature of PCD at Wilsonville is that the hot-gas enters the vessel tangentially into the vessel. There is a large cylindrical shroud in the vessel and the inlet hot-gas flows in the gap between the vessel refractory and the shroud. The purpose of the shroud is to distribute the incoming gas in the body of the filter vessel, and also to avoid impingement of the high-speed inlet gas directly on the ceramic candle filters. Figure 1 shows a schematic of the Siemens-Westinghouse Particle Control Device (PCD).

The average gas mass flow rate into the filter vessel is $2.95 \mathrm{~kg} / \mathrm{s}(23,500 \mathrm{lb} / \mathrm{hr})$, with the PCD operating at a pressure of $1344 \mathrm{kPa}(195 \mathrm{psia})$, and a temperature $1033 \mathrm{~K}\left(760^{\circ} \mathrm{C}\right)$. Under these

operating conditions, the corresponding inlet flow velocity is $9.8 \mathrm{~m} / \mathrm{s}$, the air density is $4.53 \mathrm{~kg} / \mathrm{m}^{3}$ and the air viscosity is $3.7 \times 10^{-5} \mathrm{~kg} / \mathrm{ms}$. The solid volume fraction at the inlet is typically about 0.005 to 0.025 . Therefore, the flow in bulk of the filter vessel is rather dilute. 


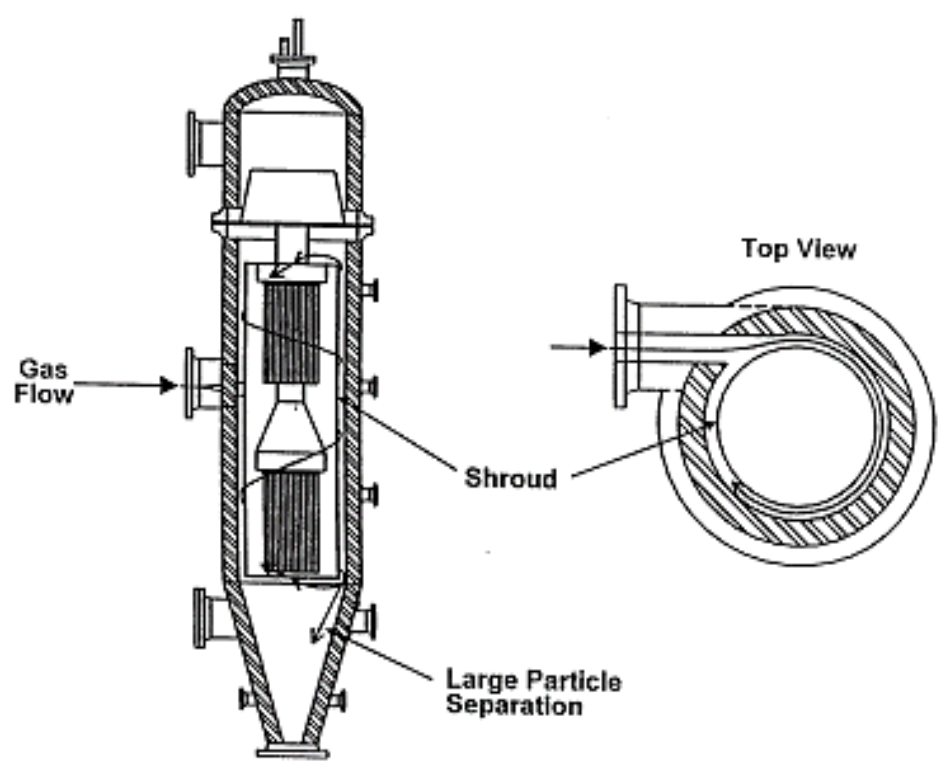

Figure 1. Schematic of the Siemens-Westinghouse Particle Control Device ( PCD) at PSDF.

\section{Equivalent Filter}

To keep the computational effort manageable, the group of 36 candle filters in the upper tier is modeled by six equivalent filters and the 55 lower filters are replaced by seven equivalent cylindrical filters. The lengths of the equivalent filters are all identical to that of the actual candle filters. All equivalent cylindrical filters, except for the one at the center of the lower cluster, have an outer diameter of $28.9 \mathrm{~cm}$ (11 in) and inner diameter of $23.9 \mathrm{~cm}(9.4 \mathrm{in})$. The one at center of the lower tier has an outer diameter of $40.6 \mathrm{~cm}$ (16 in) and an inner diameter of $34.5 \mathrm{~cm}$ (13.6 in). Figure 2 shows the schematics of the equivalent filters in the upper and lower tiers that used in the computation.

The equivalent filter diameters are selected in such a way to maintain the size and symmetry of the arrangement of groups of six ceramic filters. The permeability and the thickness of the effective cylindrical filters are adjusted so that they have the same pressure drop as the actual candle filters. The use of the seven equivalent filters in the lower tiers and six in the upper tier maintain the proper flow distribution between these filter clusters. Assuming that the candle filters have a permeability of $10^{-12} \mathrm{~m}^{2}$, the effective permeability of the upper and lower $28.9 \mathrm{~cm}$ equivalent filters is $2.033 \times 10^{-12} \mathrm{~m}^{2}$ and of the $40.6 \mathrm{~cm}$ equivalent cylindrical filter at the center of the lower tier is $3.05 \times 10^{-12} \mathrm{~m}^{2}$. 


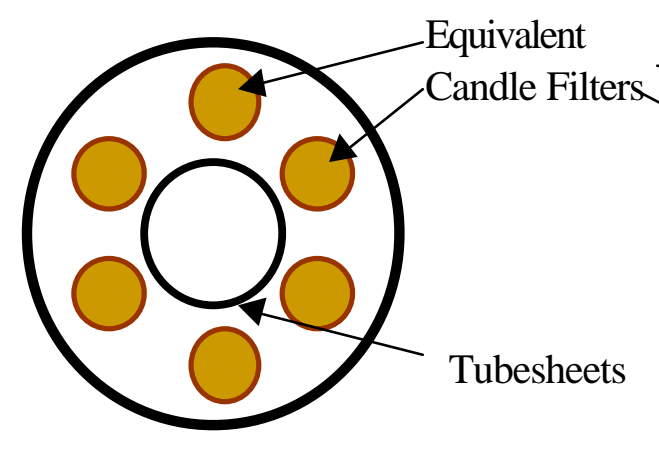

Upper Tiers

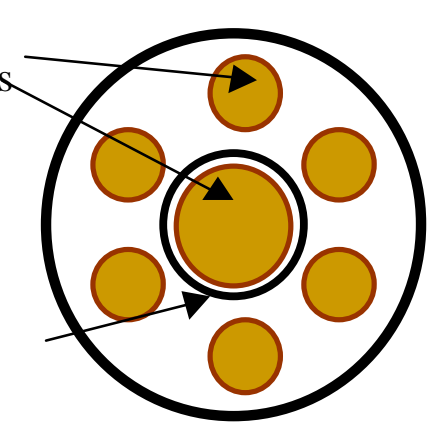

Lower Tiers

Figure 2. Schematics of the effective candle filters used in the simulation.

It should be noted here that the use of six equivalent filters in the upper tier and seven equivalent filters in the lower tier is an important improvement over the earlier work of Zhang and Ahmadi (2001). The present model provides for a proper distribution of the available filtration surface area between the upper and lower tiers. Thus, it is expected that the computed flow patterns provide for a more realistic representation of the condition in the Siemens-Westinghouse PCD.

Figure 3 identifies various surfaces of the PCD vessel for future reference in the text. The outer walls of the system are divided into four parts, the "upper wall," the "vessel side wall", the "cone wall" and the "lower wall." The "vessel side wall" denotes the straight part of the outer walls, which is about the length of the shroud. The "upper wall" denotes the part of the vessel wall, which is above the "vessel side wall." The "cone wall" denotes the conical section of the wall below the "vessel side wall." The "ash outlet wall" is the wall of the ash collection passage at the bottom of the vessel. The "shroud wall" denotes the shroud surface. The "tubesheets," are the parts to which the candle filters are attached. The "connecting post" connects the upper and the lower tubesheets.

\section{Simulation Procedure}

\section{Gas Flow Simulation}


The simulation makes use of the Reynolds stress transport model of FLUENT $^{\mathrm{TM}}$ version 5 (FLUENT User's Guide 1998 Vol. 2) for evaluating the turbulent gas flow condition in the filter vessel. In an earlier work, Ahmadi and Smith (1998a) showed that the temperature and density of gas do not vary appreciably in the NETL hot-gas filtration vessel. Similar to Zhang and Ahmadi (2001), for the present Particle Control Device, we assume that the variations of gas density and temperature to be comparatively small, and the incompressible fluid option with a constant density and temperature is used in the simulation.

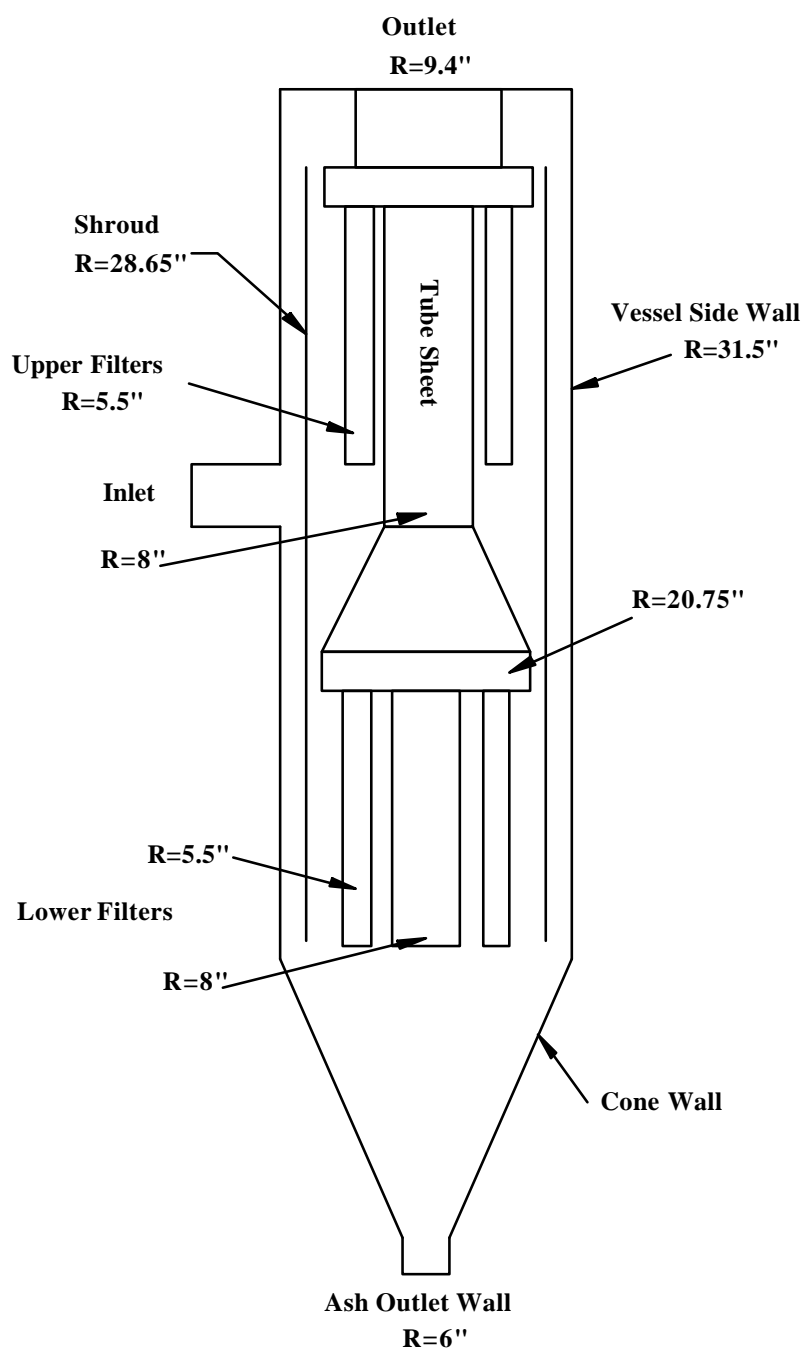

Figure 3. Schematic of the modeled filter vessel.

It should be emphasized the entire filter vessel from the inlet to the gas exhaust at the top of the vessel are simulated. In particular, the ceramic filters are treated as porous media with a given permeability, and the penetration of the gas through the filter wall is computed as part of solution. (That is there was no imposed boundary condition at the filter surface.) 


\section{Lagrangian Particle Trajectory}

We used the particle equation of motion of the code including drag and gravitational forces in the analysis. It is known that the drag force is generally dominant and the effect of lift force is small (Zhang and Ahmadi, 2001). As noted before, the mean gas velocity in the Particle Control Device is first evaluated with the use of the Reynolds stress transport model. The resulting mean flow field was then used for the mean particle trajectory analysis. A stick boundary condition for the ash particle-surface contact is assumed. That is when a particle touches a wall, it is assumed that it will stick to the surface.

\section{Simulation Results}

The gas flow and ash particle transport and deposition in the Siemens-Westinghouse filter vessel at Power System Development Facility at Wilsonville, Alabama are described in this section. The simulated turbulent gas flow field is first discussed. This is followed by analysis of different size ash particles that enter the vessel at the inlet.

\section{Computational Grid}

Due the rather complex geometry of the PCD an unstructured grid of 1,371,162 cells generated by GAMBIT code is used in the simulations. To allow a more accurate analysis of ash transport and deposition in the spacing between the shroud and vessel wall, the grid is further refined in these regions. Figure 4 shows the surface grid of the equivalent filters and at the mid-section of the vessel. In the computational model, the origin of the coordinate system is set in the center of the top of the vessel. The $\mathrm{z}$-axis is in the vertical direction pointing downward (along the gravitational direction) and the $\mathrm{x}$-axis is along the inlet flow direction.

\section{Gas Flow}

Figure 5 shows the velocity vector plot in a plane at the mid-section of the vessel. This figure shows that about half of the inlet gas moves upward in the shroud and the other half moves downward. Thus, the hot-gas enters the body of the vessel both from the top and the bottom of the shroud. The flow velocity is downward and somewhat larger in the region between the upper filter and the shroud. Near the top of the vessel, the upward gas flow in the shroud turns sharply downward to enter the mean body of the vessel. Also the downward gas flow near the outlet of the shroud at the bottom turns upward to enter the main body of the vessel. Recirculating flow regions in the lower conical part are clearly seen from Figure 5. 


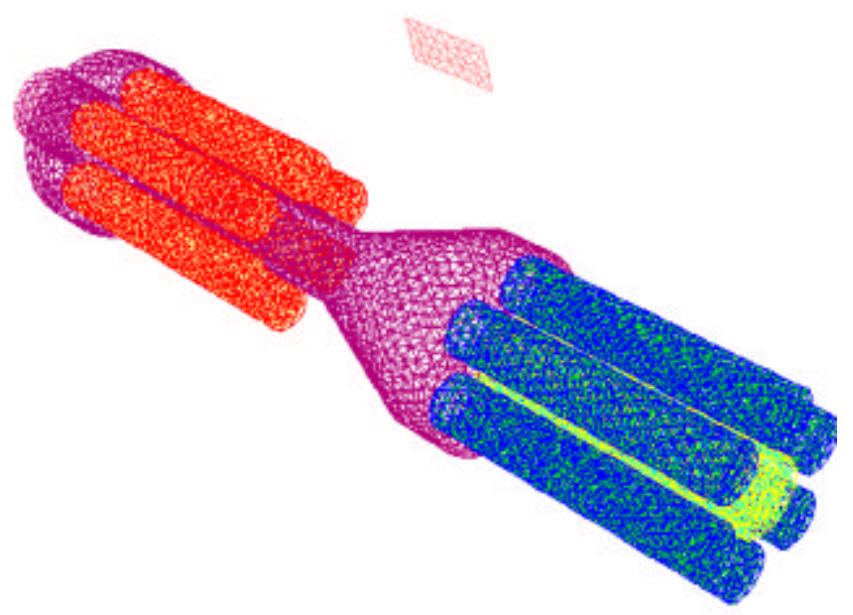

Figure 4. Grid schematic of the modeled filter vessel.

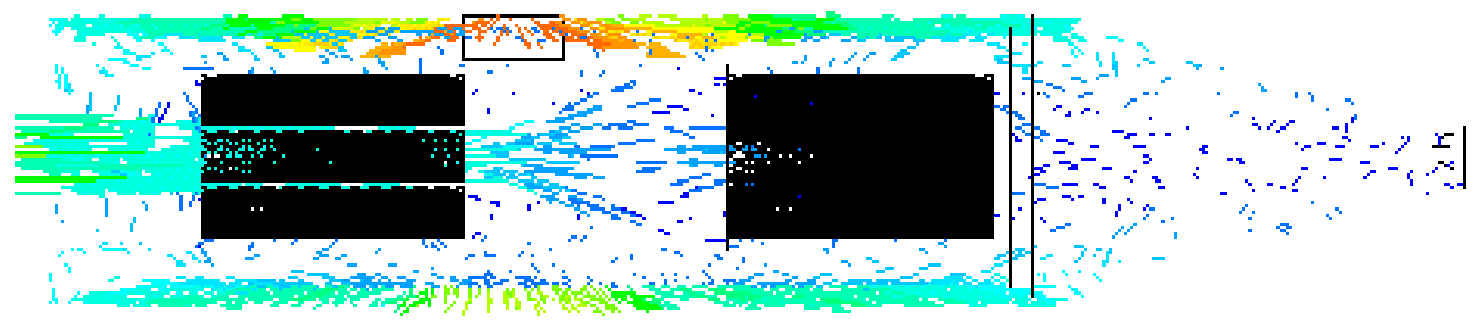

Figure 5. Velocity vector plot at the vessel mid-section.

Figure 6 shows the mean velocity magnitude contours in a plane at the mid-section of the PCD vessel. It is observed that the gas velocity inside the vessel is quite low, about $0.3-3 \mathrm{~m} / \mathrm{s}$, while is generally high, about $5-10 \mathrm{~m} / \mathrm{s}$, in the region between the vessel wall and the shroud.

Figure 7 shows the mean velocity magnitude in the plane that passes through the inlet at the $x-y$ plane. As expected, there is a strong rotating flow condition through the shroud. This figure also shows when the gas enters the body of the filter vessel from the shroud passage, it carries sufficient angular moment to sustain a noticeable rotational motion. 


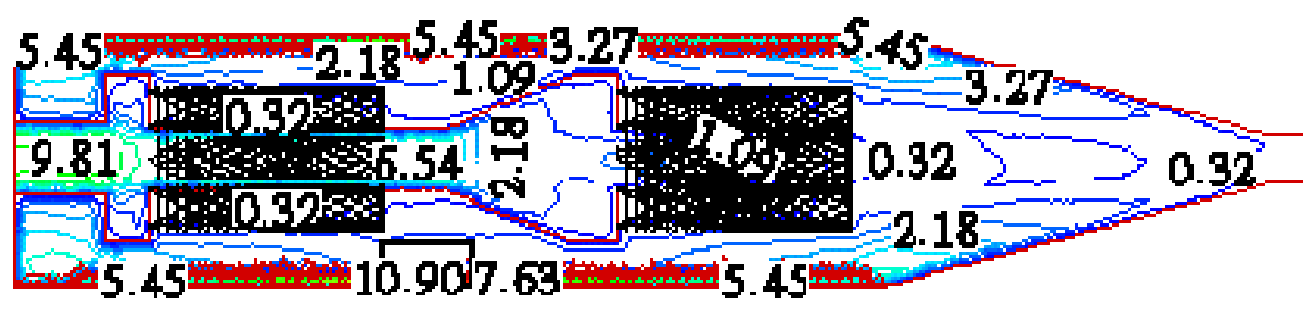

Figure 6. Mean velocity magnitude contours at the vessel mid-section.

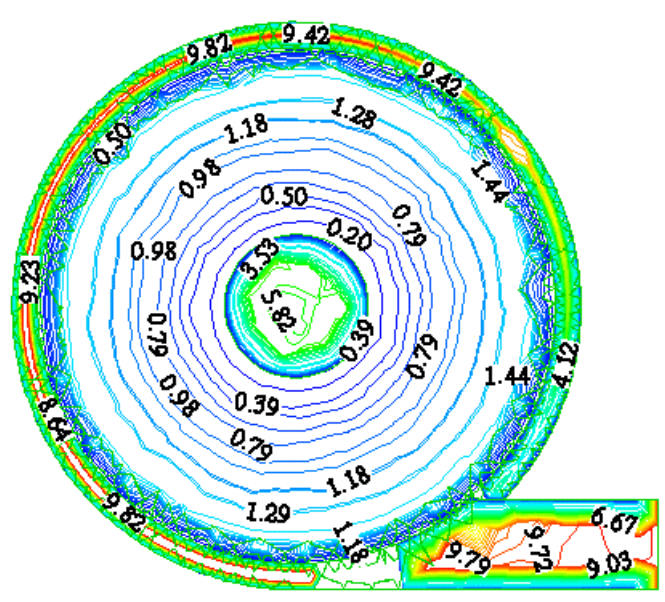

Figure 7. Mean velocity magnitude contours in a plane across the vessel and through the inlet.

The mean velocity magnitudes at the sections across the upper and lower tier filters are shown in Figure 8. This figure shows that the velocity of the gas decreases across the candle filters. The gas then penetrates into the candle filters and the gas velocity somehow increases inside of the filters and especially inside the tube sheet.

Figure 9 shows the contour plots for variations of the static pressure in a plane at the mid-section of the PCD vessel. This figure shows that the pressure remains almost constant inside the shroud and in the main body of the vessel. It is also shown that the main pressure drop occurs across the filter wall, and the pressure decreases inside the filter cavity. The air pressure inside the filter cavity and connecting pipes is 
roughly constant with a slight decrease toward the vessel outlet. It is also clearly seen the sharp pressure drop across the filter wall. It should be noted that in the body of the filter vessel the pressure is high and roughly uniform and reduces significantly as the gas passes through ceramic filter wall and enters the candle filter cavity.

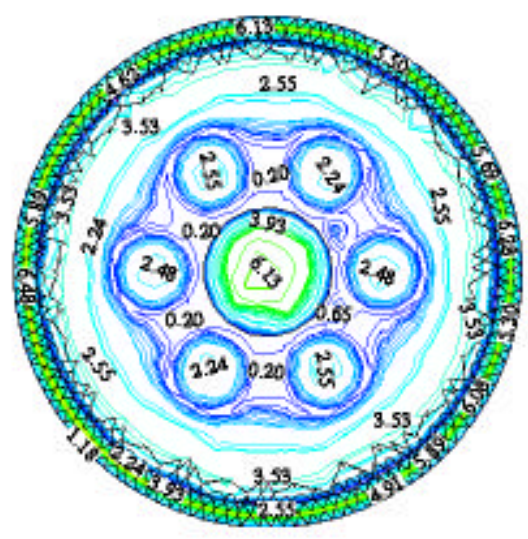

(a) Upper Tier

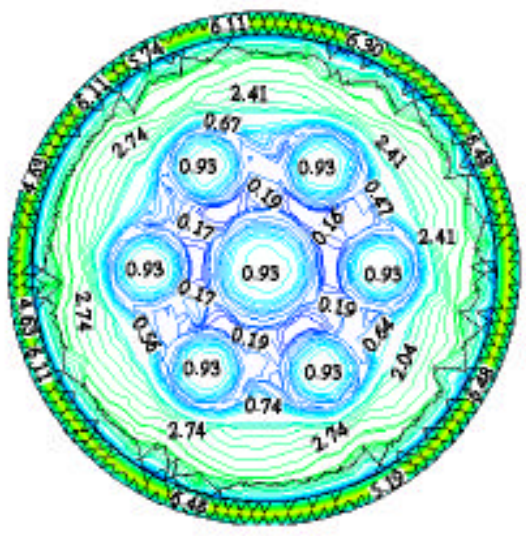

(b) Lower Tier

Figure 8 . Mean velocity magnitude contours in a plane across the upper and lower tier filters.

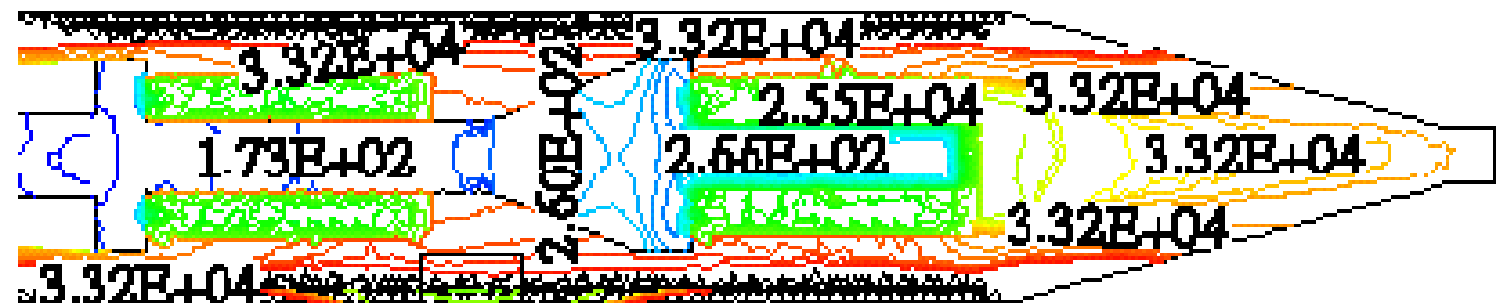

Figure 9. Contour plot for variations of the static pressure at the vessel mid-section. 
Variation of the turbulence kinetic energy in a plane at the mid-section of the filter vessel is shown in Figure 10. The turbulence kinetic energy is generally quite low in the vessel except for the certain regions inside the connecting tube.

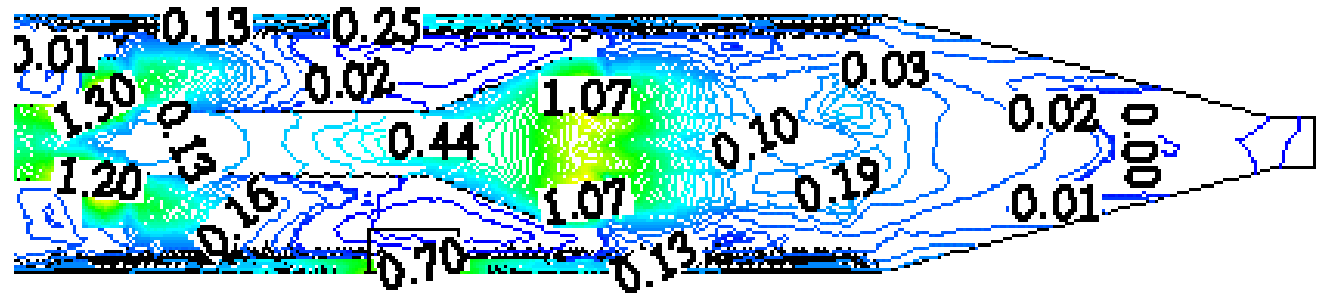

Figure 10. Turbulence kinetic energy contours at the vessel mid-section.

\section{Particle Trajectory Analysis}

Particle transport and deposition in the Wilsonville filtration system are studied using the FLUENT code. Particles with diameters of 1 and $10 \mu \mathrm{m}$ with a constant density of $2700 \mathrm{~kg} / \mathrm{m}^{3}$ are used in these computer simulations, and 348 particles of different sizes are uniformly released at the inlet with the same velocity as the gas flow. The uniform particle source is a reasonable assumption for the particle concentration condition in the inlet during the operation of the filter vessel. In these simulations, the stick boundary condition is assumed for all surfaces. For each particle size, ensembles of trajectories are evaluated and the particle deposition patterns on the different tier filters and various surfaces are analyzed.

\section{Deposition Rate}

Tables 1 shows the percentages of deposited $1 \mu \mathrm{m}$ particles on various surfaces. This table shows that about $8 \%$ of the particles are deposited on the upper filters, while about $40 \%$ of the particles are deposited on the lower filters. More importantly, about $38 \%$ of particles are deposited on the vessel wall and on the outer surface of shroud. Furthermore, it is observed that the total deposition rate on the lower filters is higher than that on the upper filters. While the particle size is small, the results show that the centrifugal force affects significantly the particle deposition rates on the areas between the vessel wall and the shroud.

Table 2 shows the simulation results for $10 \mu \mathrm{m}$ particles. It is seen that about $7 \%$ of particles deposit on the upper filters and about 20\% deposit on the lower filters. These results also show that, the total percentages of the deposited particles on the vessel wall and the outer surface of the shroud are about $60 \%$ due to the rotational motion and the importance of the centrifugal forces. It is also observed from Tables 
1 and 2 that the percentages of deposited particles on the upper and lower filters decrease as particle size increases. In addition, when particle size increases the deposition on the vessel wall increases, while deposition on the outer surface of shroud decreases.

Table 1. Percentage of the deposited $1 \mu m$ particles on different surfaces.

\begin{tabular}{|c|c|}
\hline $\begin{array}{c}1 \mu m \text { Particle } \\
\text { (FULL SHROUD) }\end{array}$ & $\begin{array}{c}\text { Percentage of Deposited } \\
\text { Particles }\end{array}$ \\
\hline Aborted & 0.6 \\
\hline Upper Filter & 8.1 \\
\hline Lower Filters (Perimeter) & 35.6 \\
\hline Lower Filter (Central) & 4.6 \\
\hline Vessel Wall & 25.9 \\
\hline Cone & 2.9 \\
\hline Inside of Shroud & 1.2 \\
\hline Outside of Shroud & 12.6 \\
\hline Central Pipe & 8.6 \\
\hline Top of Casing & 0 \\
\hline
\end{tabular}

Table 2. Percentage of the deposited $10 \mu \mathrm{m}$ particles on different surfaces.

\begin{tabular}{|l|c|}
\hline $\begin{array}{c}\mathbf{1 0} \mu m \text { Particle } \\
\text { (FULL SHROUD) }\end{array}$ & $\begin{array}{c}\text { Percentage of Deposited } \\
\text { Particles }\end{array}$ \\
\hline Aborted & 0 \\
\hline Upper Filter & 6.9 \\
\hline Lower Filters (Perimeter) & 17.8 \\
\hline Lower Filter (Central) & 3.5 \\
\hline Vessel Wall & 48.3 \\
\hline Cone & 8.2 \\
\hline Inside of Shroud & 1.2 \\
\hline Outside of Shroud & 10.9 \\
\hline Central Pipe & 3.5 \\
\hline Top of Casing & 0.6 \\
\hline
\end{tabular}




\section{Conclusions}

In this part of the project, particle transport and deposition in the hot-gas filter vessel at Power Systems Development Facility (PSDF) in Wilsonville, Alabama is studied. The FLUENT code is used to simulate the mean turbulent flow field and the corresponding particle trajectories. On the basis on the presented results, the following conclusions are drawn:

- The gas velocity magnitude inside the shroud is generally high, while it is relatively low inside the vessel.

- The main pressure drop occurs across the filter wall.

- The turbulent kinetic energy is generally quite low in the vessel, except for certain regions inside the connecting tube.

- Particles are transported by the highly swirling flows from the inlet moving both in upward and downward directions through the shroud, and then enter the main body of the vessel.

- The rotational motion and centrifugal forces are quite important for particle deposition rates in the filter vessel.

- The total number of particles that deposit on the filters, and on the central post including the tube sheet decreases as particle diameter increases.

- For startup condition (Clean filters with a constant permeability), the particle deposition rate on the lower tier filters is larger than that on the upper tier filters.

- Since the central post and the tube sheet surfaces have no cleaning mechanism, there is a potential for ash buildup and initiation of ash bridging due to the particle deposition in these regions.

- The simulation shows that a small fraction of particles could penetrate the filter cluster and deposit on the central post during the steady state filtration process.

\section{Practical Applications}

The practical application of the findings of this section for design and operation of filter vessels are:

- There is the possibility of initiation of ash bridging due to particle deposition on the solid surfaces that have no cleaning mechanics.

- The tangential flow inlet leads to a cyclone action that removes most of the large particles from the gas stream in the passage between the shroud and the vessel refractory. The filter cake that will be composed of small ash particle will have high strength and may not be effectively cleaned by the backpulse process. Thus, the potential for ash bridging due to incomplete cleaning increases.

- Computer modeling may be used to provide insight into the processes involved.

HOT-GAS FLOW AND PARTICLE TRANSPORT AND DEPOSITION IN THE SIEMENSWESTINGHOUSE FILTER VESSEL - ALTERNATE DESIGNS 
In this section the effect of design alternation on the particle transport and deposition in the Siemens-Westinghouse filter vessel at Power Development Facility in Wilsonville in Alabama is studied. As noted before for the present tangential flow vessel, modeling shows the majority of large particles (larger than $10 \mu \mathrm{m}$ ) impact the shroud or the vessel wall surfaces and are removed from the gas stream. Three alternative filter vessel designs including using a short shroud, one with no shroud and a vessel with a deflector plate are considered. The effect of design alternations on the gas flow and transport and deposition of particles of different sizes are evaluated. The simulation results suggest that it is possible to modify the shroud in a way to allow large particles to deposit on the filters. Thus, the back-pulse process could more easily remove the filter cake.

\section{Alternate Designs}

On occasions for certain coals, operational data at PSDF indicated that the filter cleaning by the back-pulse does not work effectively and ash bridging occurs. From the earlier studies, it is know that when the large size particles are removed from the gas stream, the strength of the filter cake made of small particles increases to the extent that the back-pulse cleaning may not be effective. To increase the concentration of large size particles in the filter cake, in this study several modified designs are proposed. These include using a short shroud in the vessel, operating with out the shroud, and replacing the shroud with a deflector blade.

Figure 11 shows the schematics of the vessel and its alternate designs. Figure 11a shows the schematic of the equivalent candle filters in the current vessel. This original design which contains a long shroud is referred to as "full shroud" in the subsequent discussions. Figure $11 \mathrm{~b}$ shows an alternate design for the filter vessel in which the shroud is shortened. This case will be referred to as the "short shroud" design. The "No shroud" design is shown in Figure 11c. In this case, the shroud is totally removed from the vessel. Figure 11d, shows the combination of the "no shroud" design with a deflector blade in front of the inlet. This case is referred to as the "deflector blade" design. The deflector blade used in the analysis is an airfoil shape plate.

\section{Simulation Results}

In this section, the gas flow field and transport and deposition of different size ash particles that enter the PCD at PSDF at Wilsonville, Alabama are studied. The performances of different designs are then evaluated. 


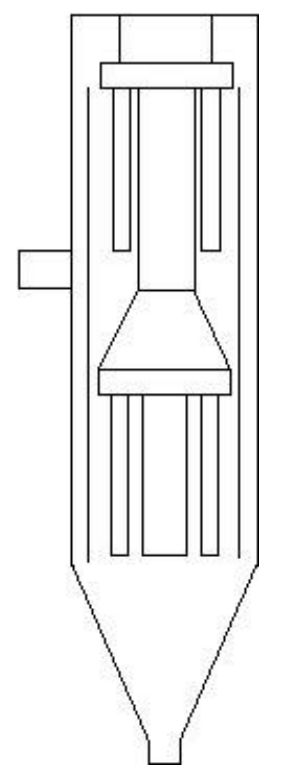

(a) Full Shroud

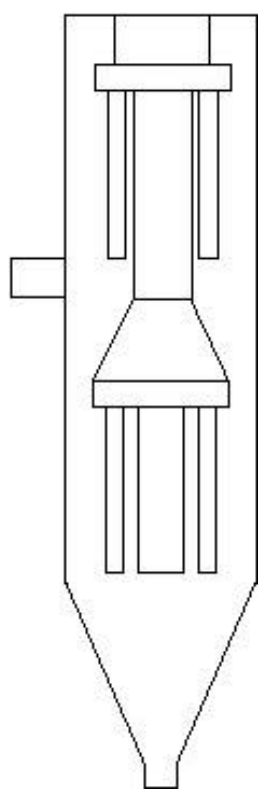

(c) No Shroud

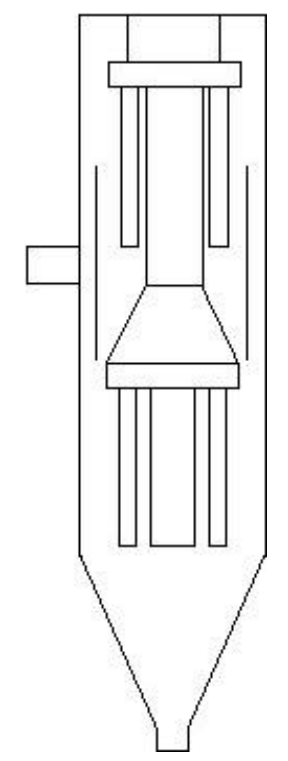

(b) Short Shroud

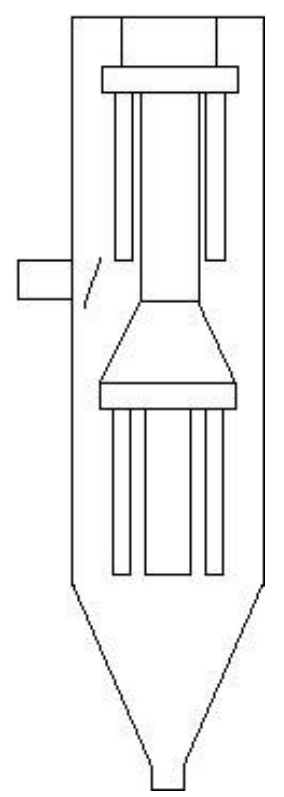

(d) Deflector Blade

Figure 11. Schematic of the filter vessel with alternate designs. 


\section{Computational Grid}

Figure 12 shows the surface grid of the different designs in the plane that passes through the inlet. The highly resolved nature of the grid near the solid walls can be clearly seen in this figure. Figure $12 \mathrm{c}$ also shows the airfoil shape of the deflector blade used in this design.

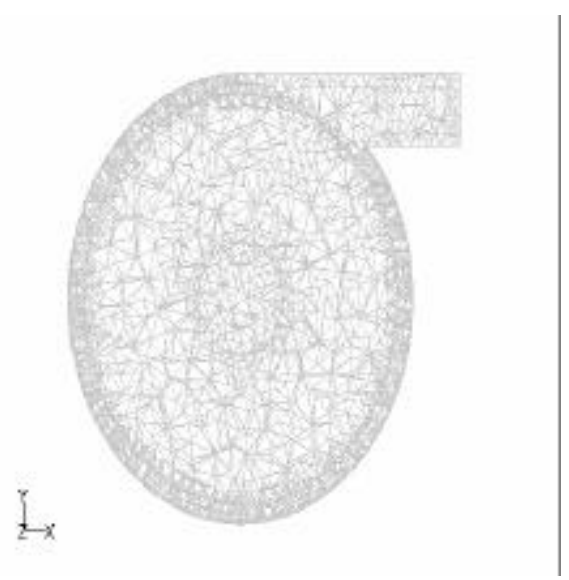

(a) Full and Short Shroud

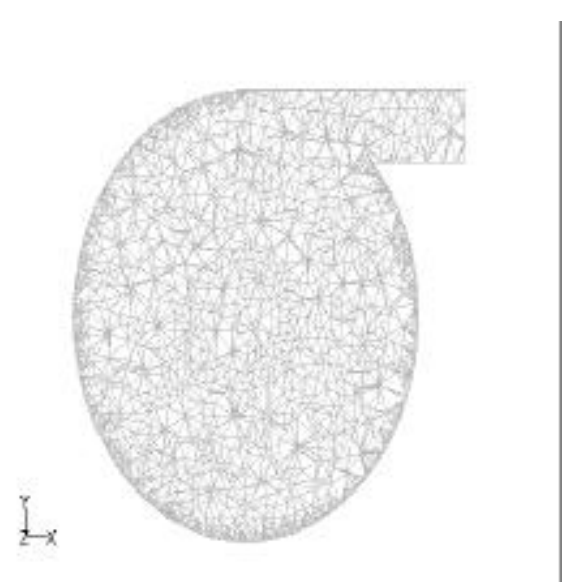

(b) No Shroud

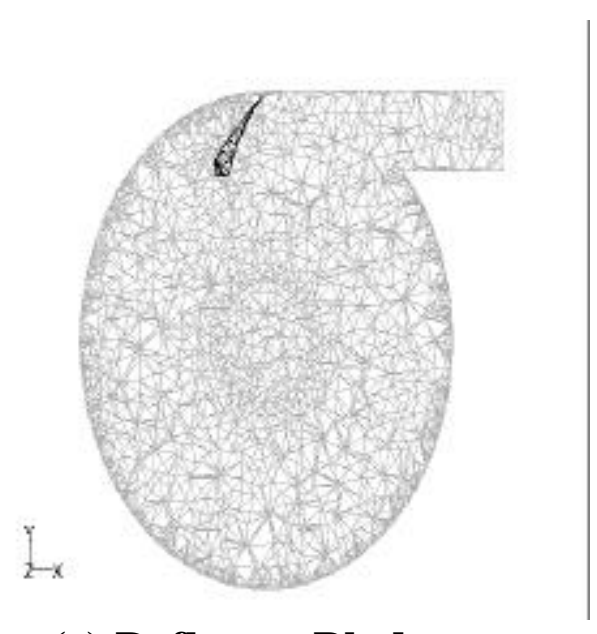

(c) Deflector Blade

Figure 12. Grid schematics of the filter vessel with alternate designs. a) Full and short shroud. b) No shroud. c) Deflector blade. 


\section{Gas Flow}

Figure 13 shows the velocity vector plots in the plane that passes through the inlet and across the filter vessel for different cases. The present design with full shroud and the alternate designs with short shroud, and when the shroud is removed in addition to the case that a deflector blade is added to the vessel are shown in this figure. Figures $13 \mathrm{a}$ and $13 \mathrm{~b}$ show that for the full and short shroud cases there is a strong rotating flow condition through the gap between the shroud and the vessel wall. The tangential velocity inside the vessel, however, is quite low in these cases. In the case with no shroud, Figure 13c shows that the peak tangential velocity near the vessel wall decreases compared to the case that the shroud is present. The region that contains high speed rotating flow inside the vessel, however, is larger and the gas velocity inside the body of the vessel is also higher than those for the full and short shroud cases. Figure 13d shows that the deflector blade changes the direction of the flow away from the wall. As a result, for the design with the deflector blade, the gas near the vessel wall has the lowest tangential velocity when compare to other cases.

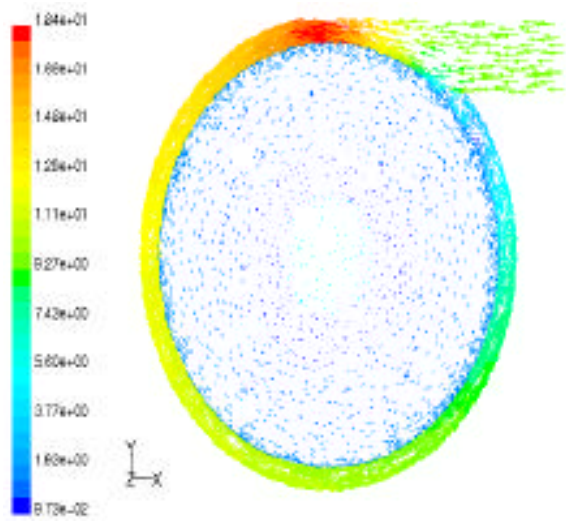

(a) Full Shroud

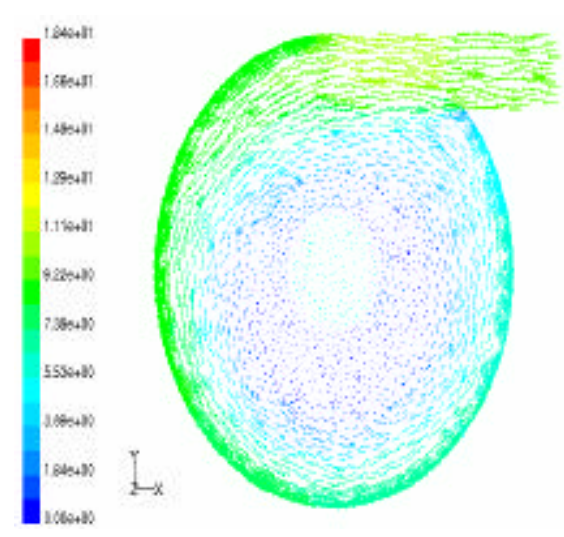

(c) No Shroud

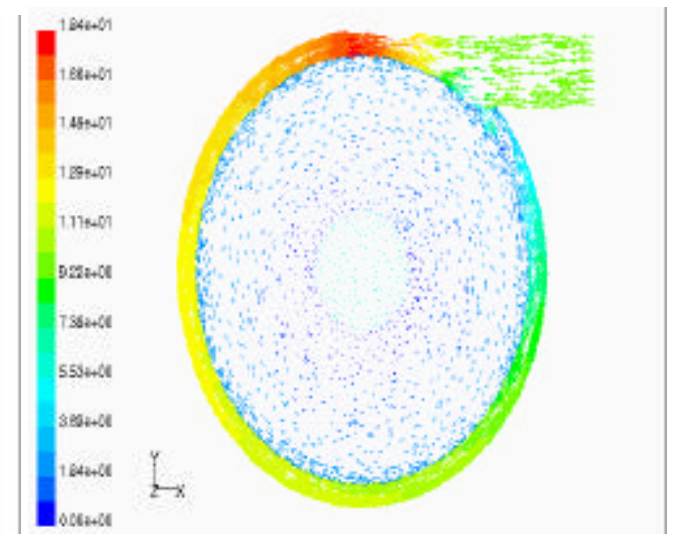

(b) Short Shroud
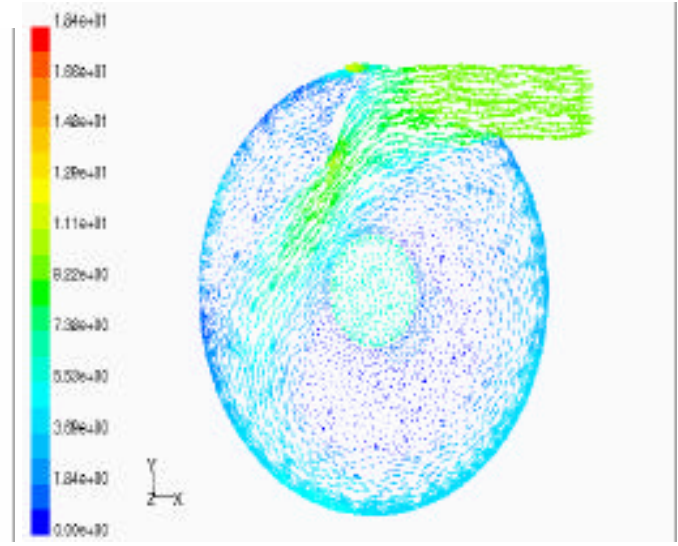

(d) Deflector Blade

Figure 13. Velocity vector plot in a plane that passes through the inlet for different designs.

The mean velocity magnitude contours in the plane that passes through the inlet for different cases are shown in Figure 14. The gas velocity magnitudes in this section for the cases with full and short shroud are 
quite similar; therefore, only one contour plot is shown. Figure 14a for the full and short shroud cases, shows that the gas velocity in the shroud passage is rather high, while inside of the body of the vessel is quite low. For the case that shroud is absent, Figure $14 \mathrm{~b}$ shows that gas velocity is relatively high inside of the body of the vessel, but its magnitude is lower near the vessel wall when compared with the cases that the shroud is present. For the vessel with the deflector blade, Figure $14 \mathrm{c}$ shows that the gas velocity near the vessel wall is quite low and blade deflects the high peed inlet gas away from the vessel wall.
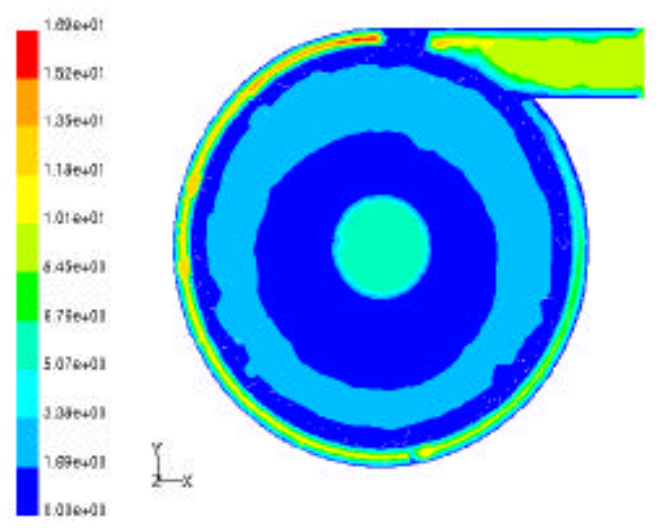

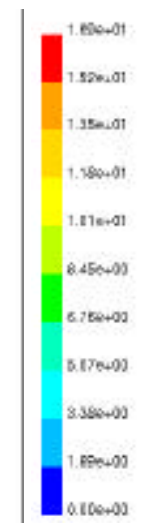

(a) Full and Short Shroud

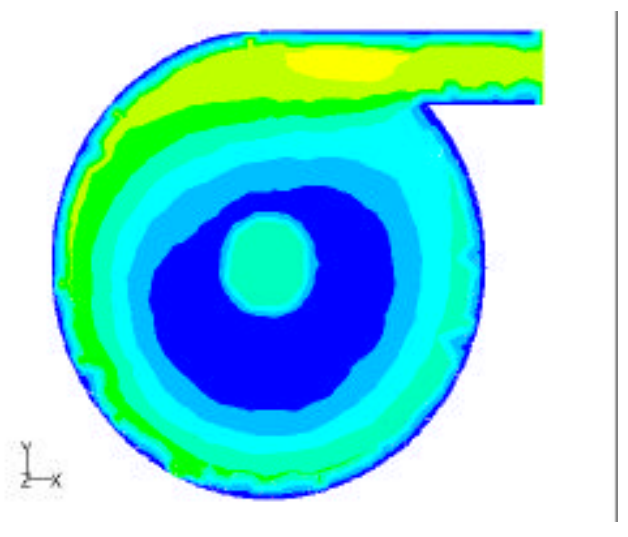

(b) No Shroud
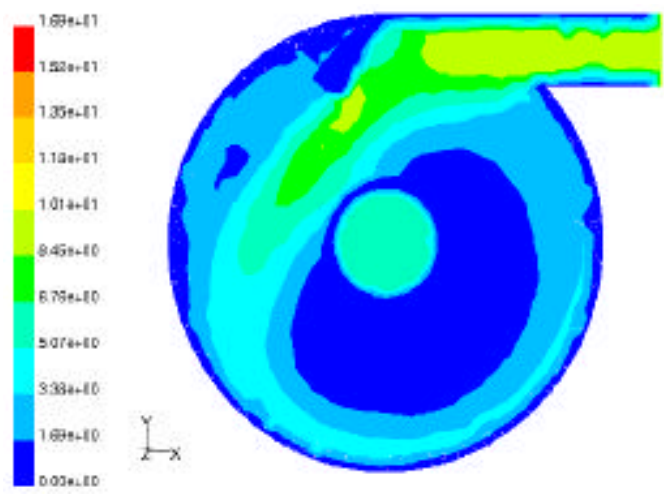

(c) Deflector Blade

Figure 14. Mean velocity magnitude contours in a plane that passes through the inlet for different designs; (a) with full and short shroud, (b) with no shroud, and (c) with deflector blade.

The velocity vector plots at the sections across the upper tier filters for various vessel designs are shown in Figures 15. This figure shows that the high-speed tangential velocity of the gas inside the shroud persist in the entire length of the shroud. The tangential gas velocity in body of the vessel is larger for the case with short shroud as compared with those with the full shroud. The tangential gas velocity in body of the vessel is larger for the case with short shroud as compared with those with the full shroud. Similarly, 
the gas velocity in the body of the vessel increases in the absence of the shroud. The vessel with the deflector blade appears to have the lowest mean velocity field.
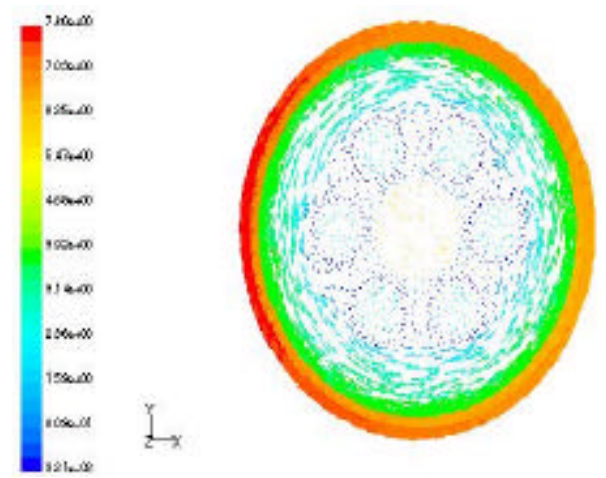

(a) Full Shroud

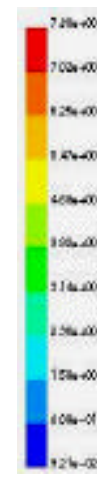

(c) No Shroud
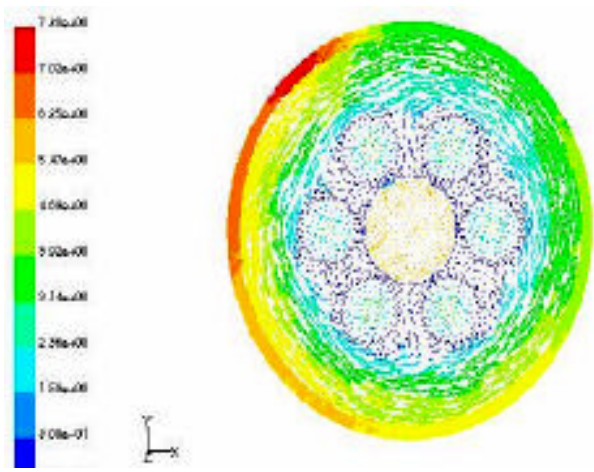

(b) Short Shroud

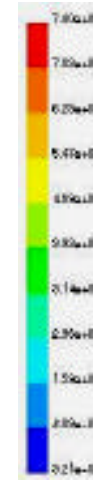

h.

(d) Deflector Blade

Figure 15. Mean velocity vector plots in a plane across the upper filters for different designs; (a) with full shroud, b) with short shroud, c) with no shroud, and d) with deflector blade.

Figure 16 show the velocity vector plots at the sections across the lower tier filters for various vessel designs. The variations of the mean velocity field are comparable to those shown in Figure 15 for the upper tiers. The tangential gas velocity in vessel body as the shroud becomes shorter or removed. The vessel with the deflector blade again leads to the lowest mean velocity field. 

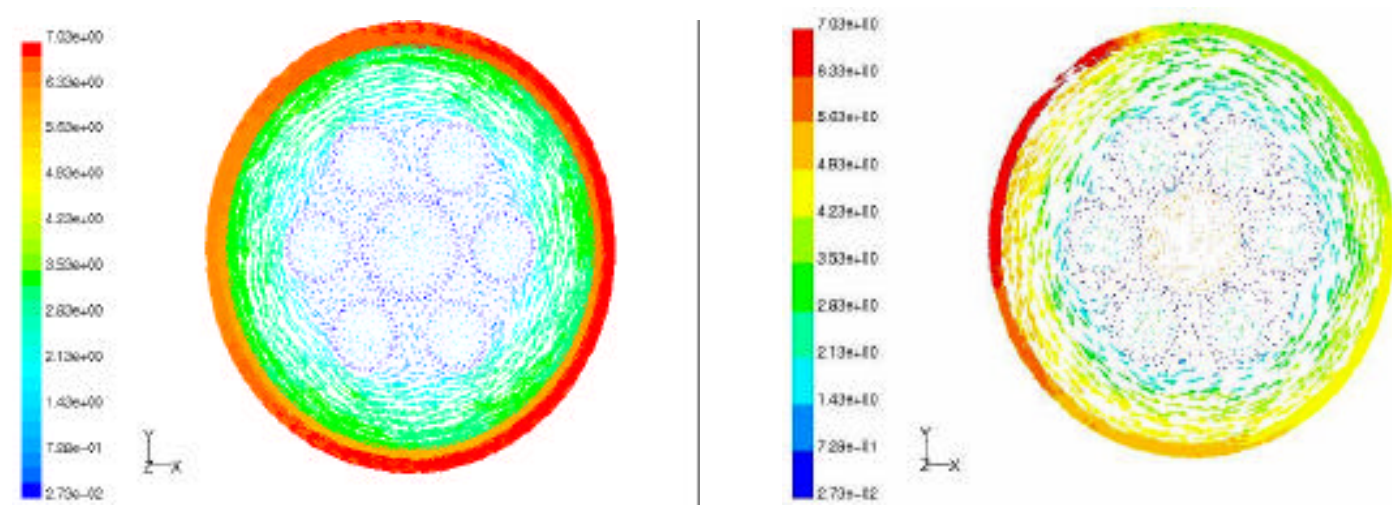

(a) Full Shroud

(b) Short Shroud

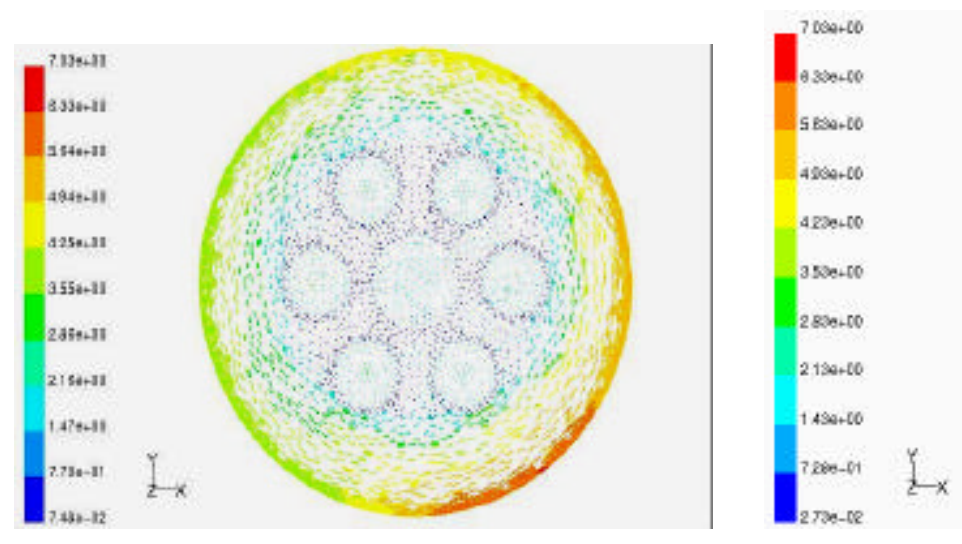

(c) No Shroud

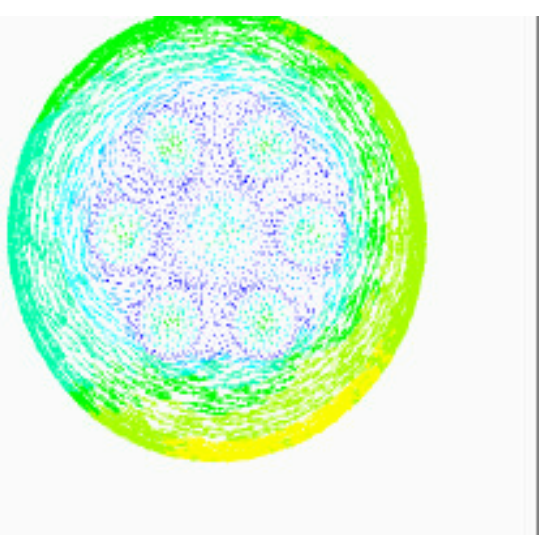

(d) Deflector Blade

Figure 15. Mean velocity vector field (colored with magnitude) in a plane across the lower filters for different designs; (a) with full shroud, (b) with short shroud, c) with no shroud, and (d) with deflector blade.

Figure 16 show the mean velocity magnitude contours for the vessel with the deflector blade case in a plane at the mid-section of the vessel and at sections across the upper and lower filters. This figure clearly shows that the deflector blade turns the high-speed inlet gas from the wall. It is also seen that the gas 
velocity is relatively high near the ceramic filters at the level of deflector blade, while the velocity becomes comparatively low inside the body of the vessel away from the blade.

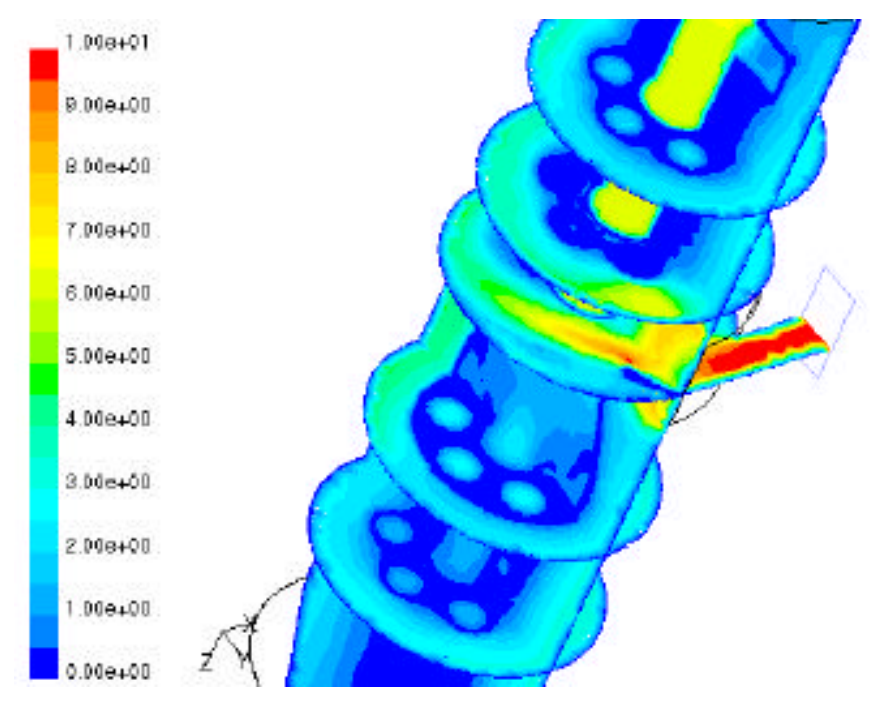

Figure 16. Mean velocity magnitude contours for the vessel with the deflector blade.

Figure 17 shows the pressure drop contours in a plane that passes through the inlet for different filter vessel designs. Figure 17a shows that in the full-shroud case, the pressure drop is $33528 \mathrm{~Pa}$, while for the short shroud case the pressure drop decreases by about $200 \mathrm{~Pa}$ to $33331 \mathrm{~Pa}$. For the cases with no shroud and with deflector blade, Figures $9 \mathrm{c}$ and $9 \mathrm{~d}$ show that the maximum pressure drop are 33177 and $33300 \mathrm{~Pa}$. These trends are as expected since the resistance of the flow field is the least for the vessel with no shroud and highest for the case with full shroud. The vessels with the short shroud and the deflector blade generate about the same pressure drops with about $30 \mathrm{~Pa}$ difference. 


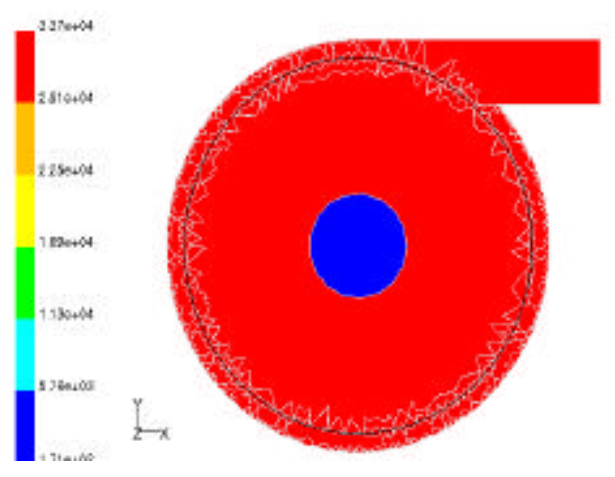

(a) Full Shroud

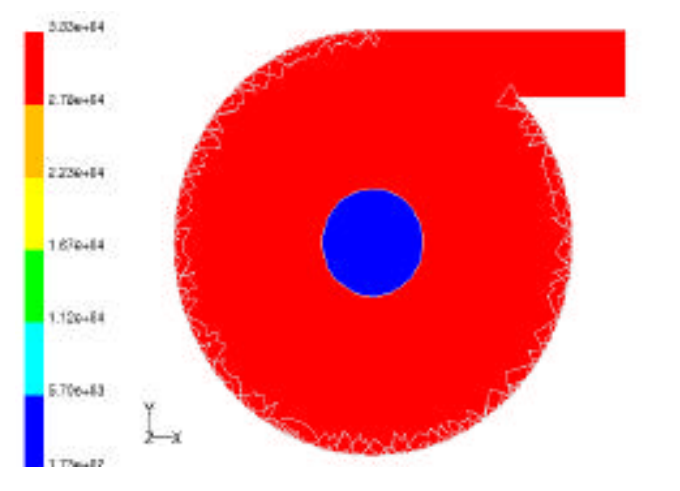

(c) No Shroud
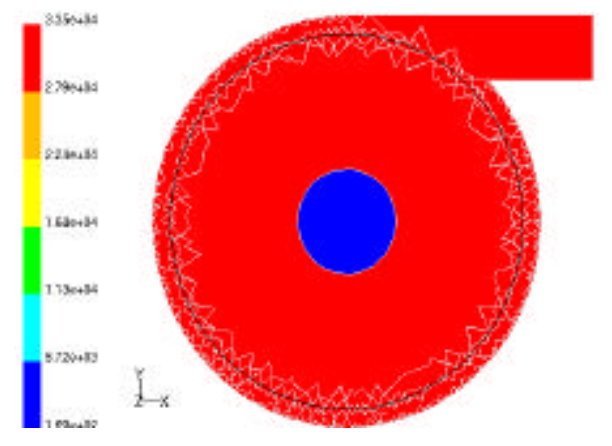

(b) Short Shroud
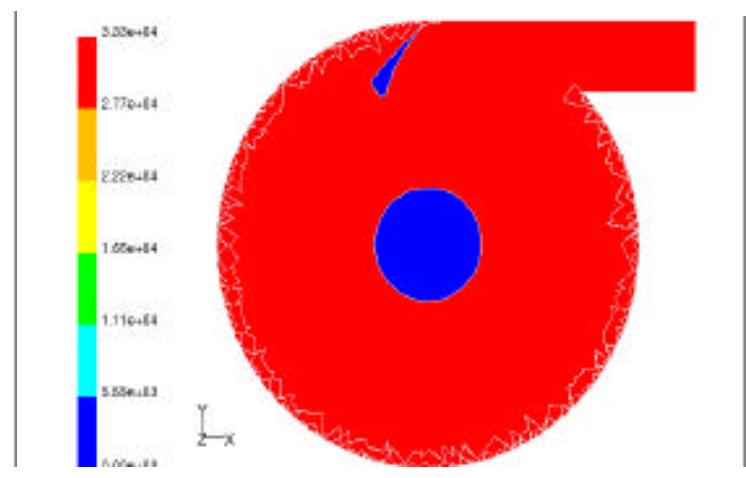

(d) Deflector Blade

Figure 17. Pressure drop contour in a plane that passes through the inlet for different designs; (a) with full shroud, (b) with short shroud, c) with no shroud, and (d) with deflector blade.

Particle Trajectory Analysis

Particle transport and deposition in the Wilsonville filtration system with several modified designs are studied using the FLUENT code. Particles with diameters of 1 and $10 \mu m$ with a constant density of $2700 \mathrm{~kg} / \mathrm{m}^{3}$ are used in these computer simulations. Particles of different sizes are uniformly released at the inlet with the same velocity as the gas flow. In these simulations, the stick boundary condition is assumed for all surfaces. For each particle size, ensembles of trajectories are evaluated and the particle deposition 
patterns on the different tier filters and various surfaces are analyzed. Performances of the filter vessel with different designs are analyzed.

\section{Deposition Rate}

Tables 3 shows the percentage of deposited $1 \mu \mathrm{m}$ particles on various surfaces for different filter vessel designs. This table shows that for the full shroud design (the current vessel), about $38 \%$ of the 1 $\mu m$ particles are deposited on the vessel wall and the outer surface of the shroud, while for the vessel with the deflector blade only about $9 \%$ of the particles are deposited on these surfaces. It is also observed that in the deflector blade case, the total deposition rate on the lower and upper filters is higher than the other cases. Furthermore, while in the full shroud case, the total deposition rate on the lower tier is much higher than that on the upper filters, for the deflector blade case they are almost the same. For the vessel with short shroud, the distribution of the deposition on the upper and lower tier filters are more uniform, but the amount of the deposition is comparable to that for the full shroud case. The performance of vessel with no shroud is somewhere between the full shroud case and the vessel with the deflector blade. In the case the deposition on the filters increases and the wall deposition is reduced.

Table 3. Percentage of the deposited $1 \mu m$ particles on different surfaces for different cases.

\begin{tabular}{|l|c|c|c|c|}
\hline \multicolumn{1}{|c|}{ Specific Area } & BLADE & SHORT Shroud & No-Shroud & Full-Shroud \\
\hline Upper Filters & 36.11 & 20.90 & 29.31 & 8.06 \\
\hline Lower Filters & 35.00 & 26.62 & 24.71 & 40.23 \\
\hline Vessel Wall & 9.44 & 29.60 & 14.94 & 25.86 \\
\hline Outside of Shroud & N/A & 7.21 & N/A & 12.64 \\
\hline Inside of Shroud & N/A & 1.24 & N/A & 1.15 \\
\hline Vessel Cone & 3.33 & 5.72 & 12.64 & 2.87 \\
\hline Central Pipe & 3.33 & 3.23 & 6.9 & 8.62 \\
\hline Blade & 9.44 & N/A & N/A & N/A \\
\hline Remain Suspended & 3.33 & 5.47 & 11.49 & 0.57 \\
\hline
\end{tabular}

Table 4 shows the simulation results for $10 \mu m$ particles. It is seen that in the full shroud case, about $60 \%$ of $10 \mu \mathrm{m}$ particles deposit on the vessel wall and the outer surface of the shroud, and only about $28 \%$ of the particle get to the filters. On the other hand, for the vessel with the deflector blade only about $12 \%$ of particles deposit on the vessel solid surfaces, while more that $64 \%$ of the $10 \mu \mathrm{m}$ particles are deposited on the ceramic filters. The performance of the vessel with the short shroud is quite similar to that with the full shroud. In appears that the centrifugal force generate in the shroud leads to the deposition of large particles near the inlet. Thus, the length of the shroud (in range considered in this study doe not affect the deposition rate to a significant extend. The case with no shroud, however, improves the deposition 
pattern in respect to increasing the amount of large size particles in the filter cake composition. Here about $41 \%$ of $10 \mu \mathrm{m}$ particles reach the candle filters. It is also observed from Tables 3 and 4 that in all the cases, the percentages of deposited particles on the candle filter decrease as particle size increases.

To fully understand the performance of the different designs in the nature of filter case produced we need to compare the composition of the resulting filter cake. Assuming that the inlet ash has equal concentrations of 1 and $10 \mu \mathrm{m}$ particles, Tables 5 shows the composition of the filter case for different designs. It is seen that the current vessel with full shroud and the one with a short shroud generate filter cakes where the amount of $1 \mu \mathrm{m}$ particles is about twice that of $10 \mu \mathrm{m}$ particles. For the case with no shroud the filter cake is composed of about $47 \% 1 \mu \mathrm{m}$ particles and 53\% $10 \mu \mathrm{m}$ particles. The design with the deflector blade has the highest percentage of large particle (about 47\%). Thus the present comparison of various designs, in Tables 3 - 5 suggest that the use of the deflector blade instead of the shroud will help to increase the concentration of larger particles in the filter cake and thus improve the effectiveness of back-pulse cleaning.

Table 4. Percentage of the deposited $10 \mu m$ particles on different surfaces for different cases.

\begin{tabular}{|l|c|c|c|c|}
\hline \multicolumn{1}{|c|}{ Specific Area } & BLADE & SHORT Shroud & No-Shroud & Full-Shroud \\
\hline Upper Filters & 36.11 & 16.17 & 25.86 & 6.90 \\
\hline Lower Filters & 27.78 & 6.72 & 15.51 & 21.27 \\
\hline Vessel Wall & 12.22 & 46.77 & 39.66 & 48.28 \\
\hline Outside of Shroud & N/A & 9.45 & N/A & 10.92 \\
\hline Inside of Shroud & N/A & 1.0 & N/A & 1.15 \\
\hline Vessel Cone & 6.67 & 6.47 & 19.54 & 8.05 \\
\hline Central Pipe & 3.33 & 1.99 & 0 & 3.45 \\
\hline Blade & 11.67 & N/A & N/A & N/A \\
\hline Remain Suspended & 2.23 & 1.00 & 7.47 & 0 \\
\hline
\end{tabular}

Table 5. Filter cake composition for the case of a uniform inlet concentration of 1 and $10 \mu m$ particles for different designs.

\begin{tabular}{|l|c|c|}
\hline & $1 \mu m$ Particles & $10 \mu m$ Particles \\
\hline
\end{tabular}




\begin{tabular}{|c|c|c|}
\hline Full Shroud & $63.3 \%$ & $36.7 \%$ \\
\hline Short Shroud & $67.5 \%$ & $32.5 \%$ \\
\hline No Shroud & $56.8 \%$ & $43.2 \%$ \\
\hline Deflector Blade & $52.7 \%$ & $47.3 \%$ \\
\hline
\end{tabular}

\section{Conclusions}

In this section, performances of the hot-gas flow and particle transport and deposition in the Siemens-Westinghouse filter vessel with alternate designs are studied. The mean turbulent flow field in the vessel is numerically evaluated and the corresponding ash particle trajectories are simulated. On the basis on the results presented, the following conclusions are drawn:

- The current design with tangential flow and full or short shroud generate large centrifugal forces that remove a large fraction of large particles from the gas stream.

- Removing the shroud will increase the deposition rate of larger particles on the candle filters.

- The new proposed design where a deflector blade in the front of the inlet replaces the shroud produces filter cakes with largest percentages of larger particles.

- The gas speed near the vessel wall is largest for the vessels with a shroud and lowest in the design with the deflector blade.

- The gas velocity inside the body of the vessel is lowest for the vessel with the full shroud (current design).

- The gas speed is relatively high inside the vessel for the vessel with the deflector blade when compared with the other cases.

- The rotational motion and centrifugal forces significantly affect the ash deposition rates in the filter vessels with a tangential inlet.

- Percentages of the ash particle deposited on the upper and lower tier filters are almost equal for the deflector blade design, while in full and short shroud cases the particle deposition rates on the lower filters is higher than that on the upper filters.

\section{Practical Applications}

The practical application of the findings of this section for design improvement of industrial filter vessels are:

- Alternate designs for reducing the rotational flow in the vessel due to the presence of the tangential flow inlet are provided. Deflector blade appears to be most effect for this purpose. Removing the shroud 
is also partially effective. These design modifications are expected to introduce additional amount of large particles in the gas stream. As result, the filter cake will have a lower strength and be more effectively cleaned by the backpulse process. This will then reduce the potential for ash bridging due to incomplete cleaning.

- Computer simulations could be used to test the performance of various design alterations.

\section{EXPERIMENTAL STUDY}

A laboratory-scale model of a hot-gas filter vessel for cold flow testing was deigned and fabricated. A picture of the laboratory-scale vessel that using three half-meter long silicon carbide candle filters is shown in Figure 18. The model uses three candle filters, arranged in a triangular pattern around a center post that supports the tubesheets. The main body of the experimental vessel is a 12-inch diameter Plexiglas cylinder to allow for visual inspection of the gas flow conditions. The support column, the base plate, and the top enclosure including the inlet pipe are made of steel. While the operational temperature of the laboratory scale model is quite different from those of the demonstration-scale vessels, it is expected that the general features of the gas flow and ash particle transport processes to be quite similar.

The flow visualization is achieved using glycerin particles from a Rosco fogger machine. This machine heats the glycerin until it vaporizes and forms a fog of small droplets. The fog is fed into a mixing chamber so that controlled amount of the fog enters the filter vessel. The exhaust gas of the filter vessel is passed though a water filter to removal any remaining droplets.

To visualize the flow patterns in the filter vessel, a laser sheet is created in a plane across the filters or along the filters, through the Plexiglas cylinder. Pictures of the flow pattern generated by the laser sheet illumination across the filters in the experimental setup are shown in Figures 19 and 20. Illumination of the glycerin droplets allows the flow patterns to be seen. Additional details

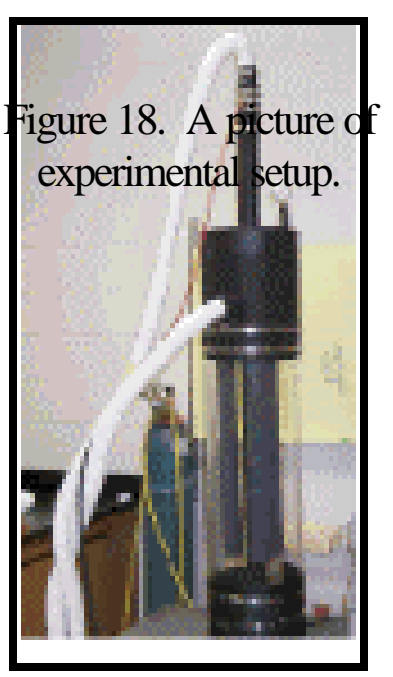
can be seen in the movies at http://www.clarkson.edu/projects/nsfreu/whitetk/horiz.html and http://www.clarkson.edu/projects/nsfreu/whitetk/vert.html

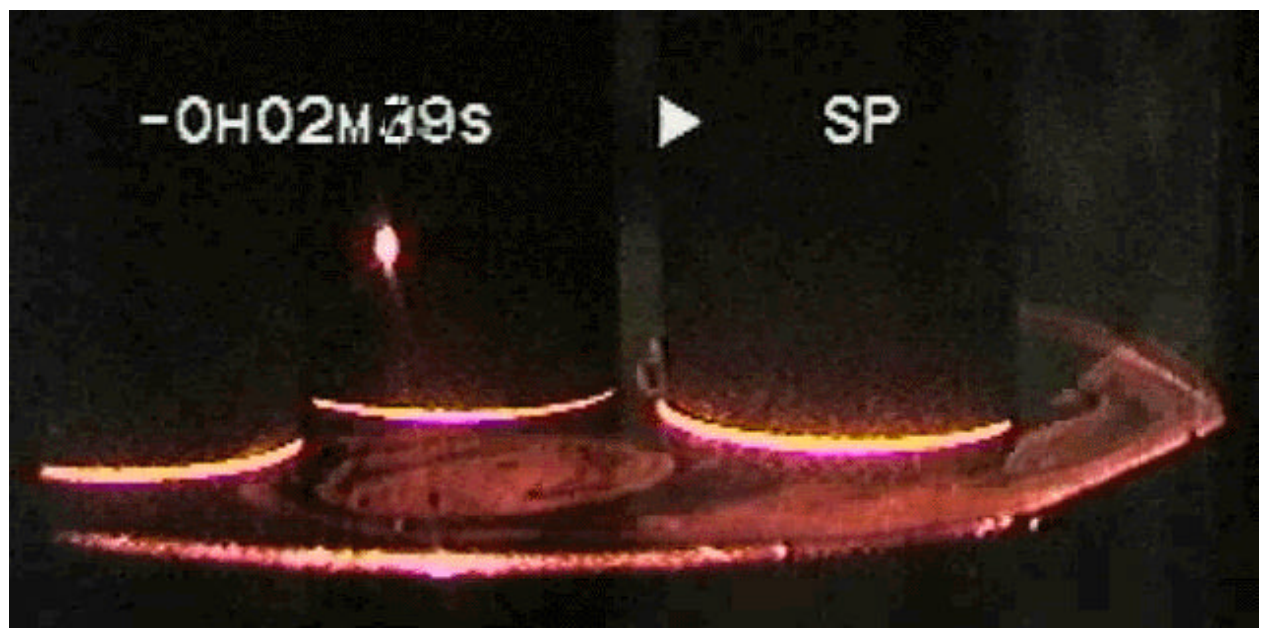




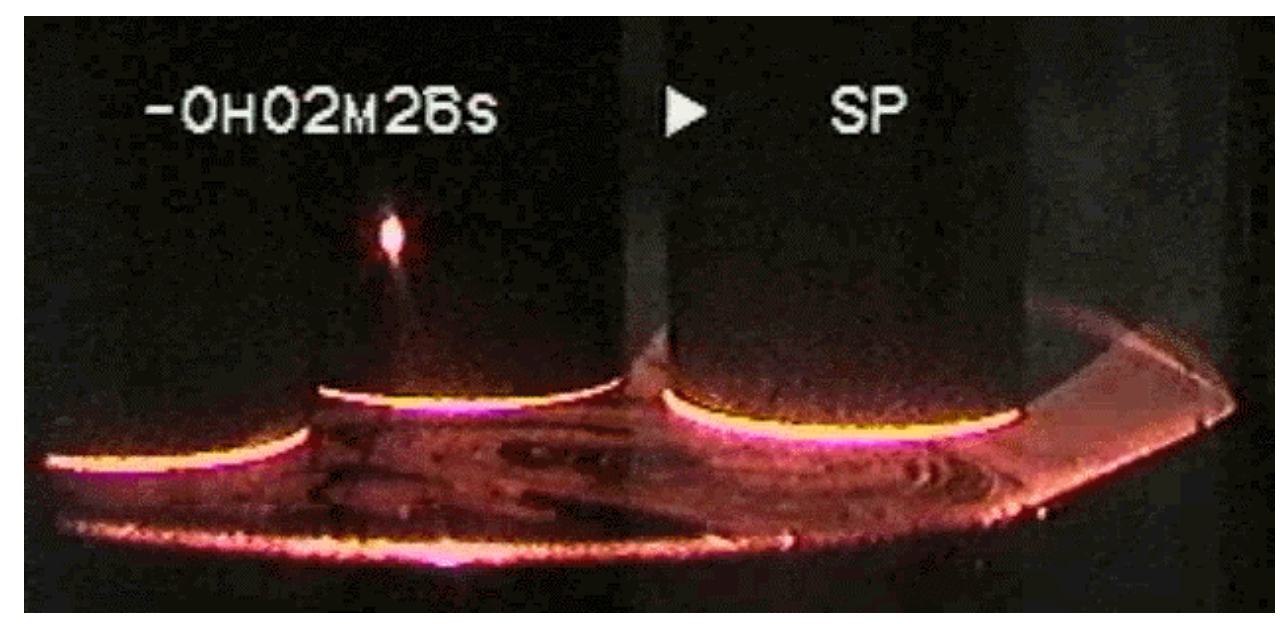

Figure 19. Laser sheet illumination of flow patterns in a plane across the candle filters.

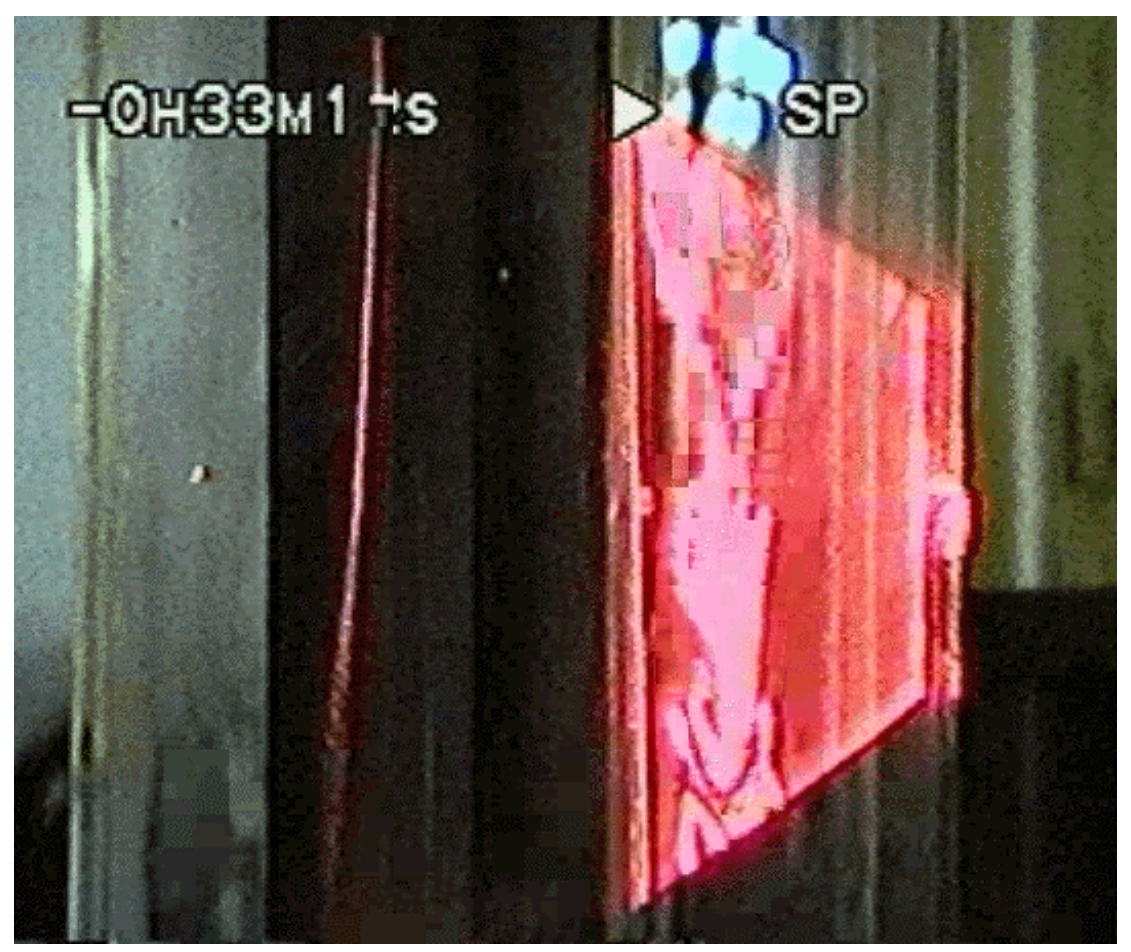




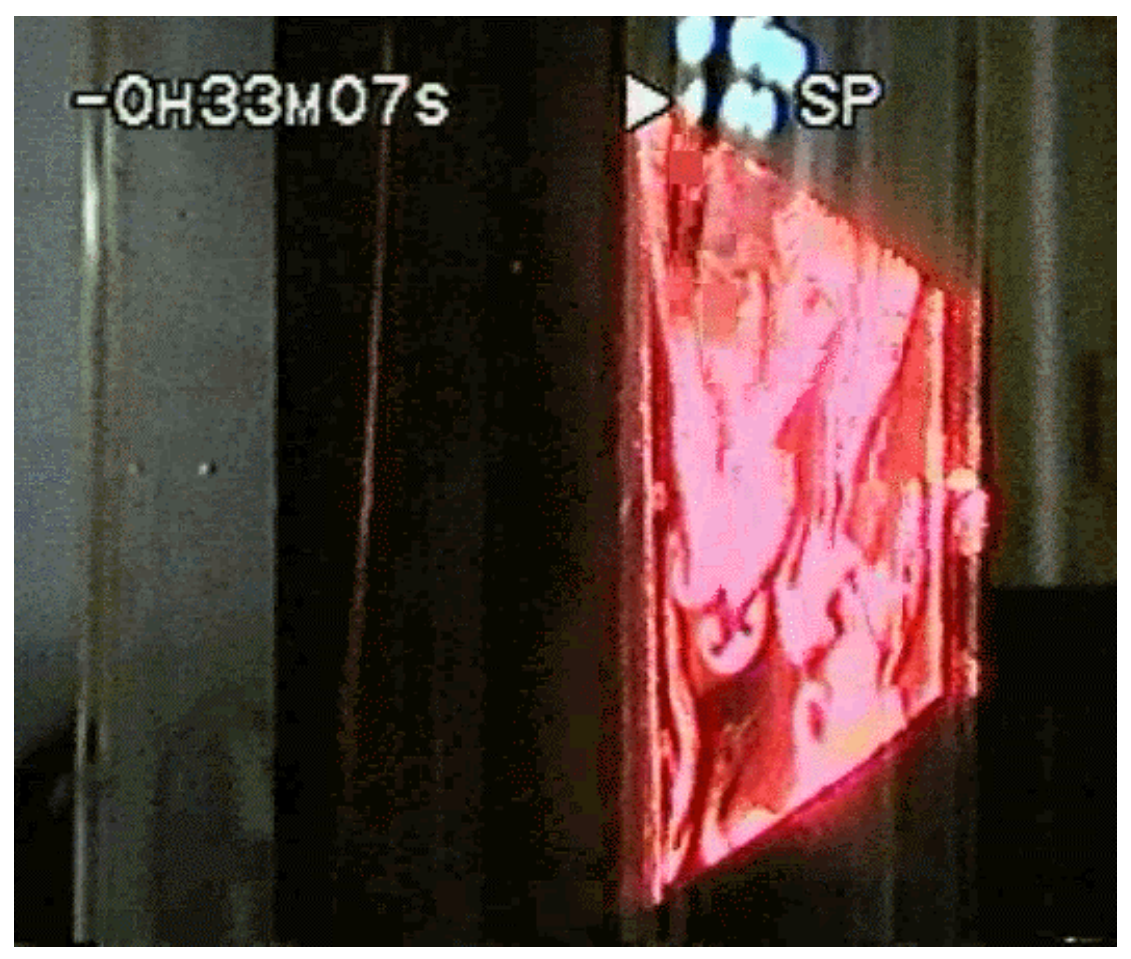

Figure 20. Laser sheet illumination of flow patterns in a plane along the candle filters.

\section{TEMPERATURE DISTRIBUTION IN SIEMENS-WESTINGHOUSE FILTER VESSEL WITH ASH BRIDGING}

In this section, variation of temperature distribution in the Siemens-Westinghouse filter vessel at Power Development Facility in Wilsonville in Alabama is studied as an example. Particular attention was given to the effects of ash bridging on the temperature variation in the vessel. The gas mean velocity, root mean square fluctuation velocities and the temperature distribution in the filter vessels with and without ash bridging are evaluated. The computational result suggests that ash-bridging lead to a non-uniform temperature distribution along the ceramic candle filters in the bridging region.

In a recent experimentation (Foote, 2002) ash bridging in the lower tiers of the SiemensWestinghouse filter vessel is observed. The schematics of the observed ash bridging and the equivalent filter model are shown in Figure 21. 


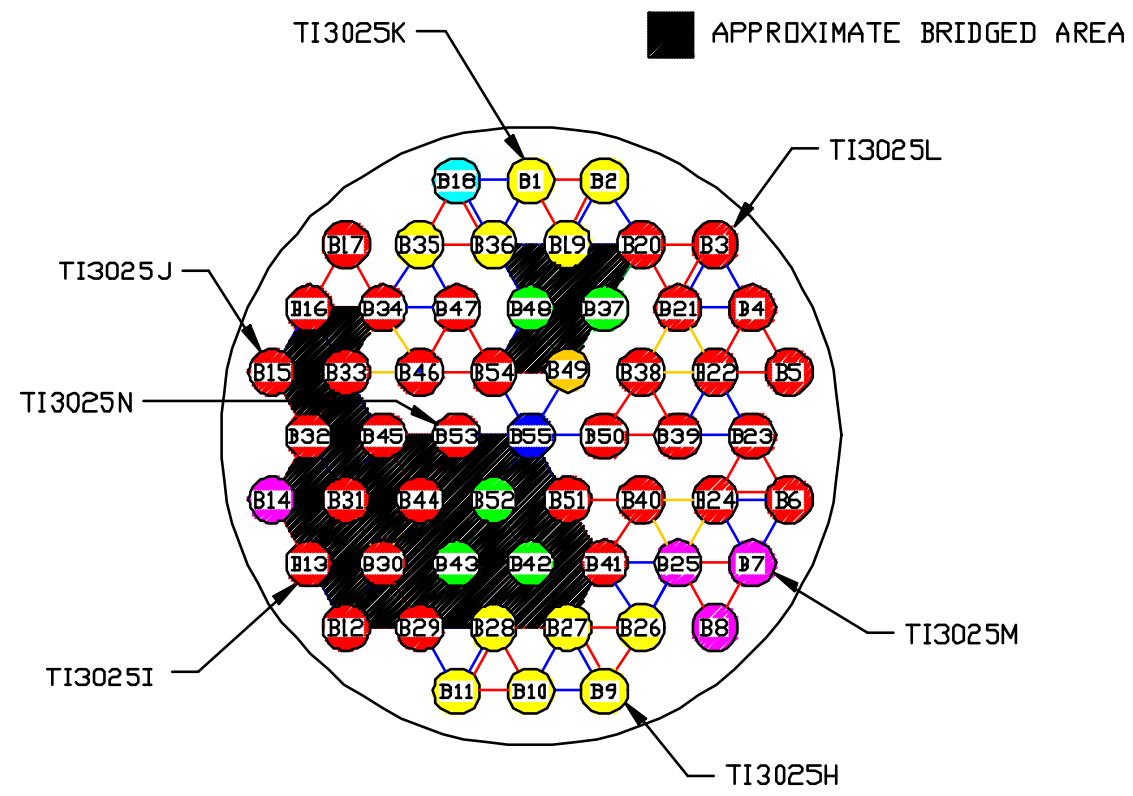

Figure 21. Schematics of the ash bridging as observed during the operation of Siemens-Westinghouse filter vessel (Foote, 2002).

\section{Computational Grid}

An unstructured grid of about 700,000 cells generated by GAMBIT code was used in these simulations. Figures 22 and 23 show the schematic of the grids of the equivalent filter model in the presence of the ash bridging, and the corresponding computational grid used.
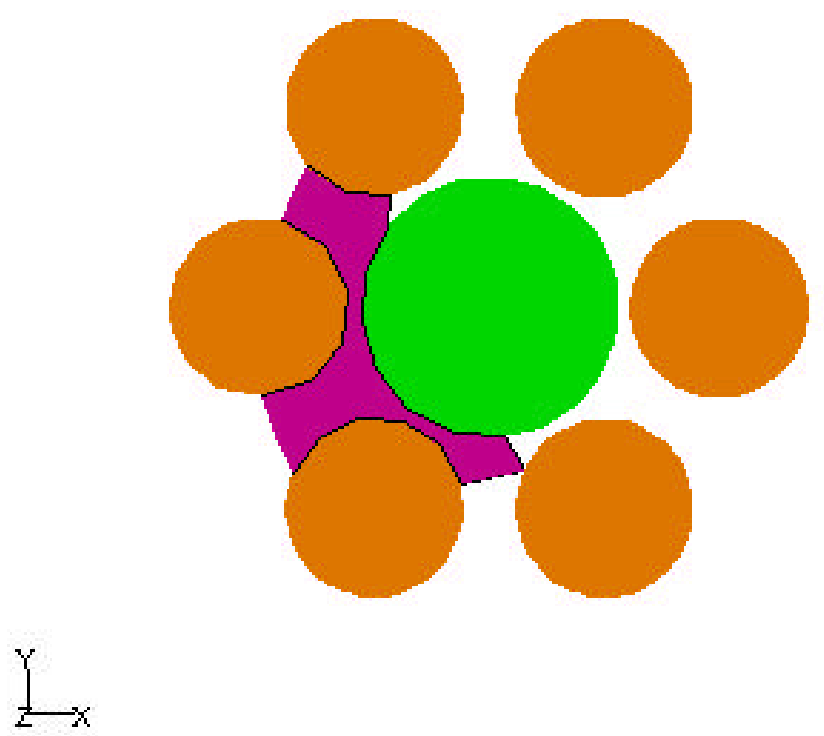
Figure 22. Schematics of the computational model of the ash bridging and the effective filters.

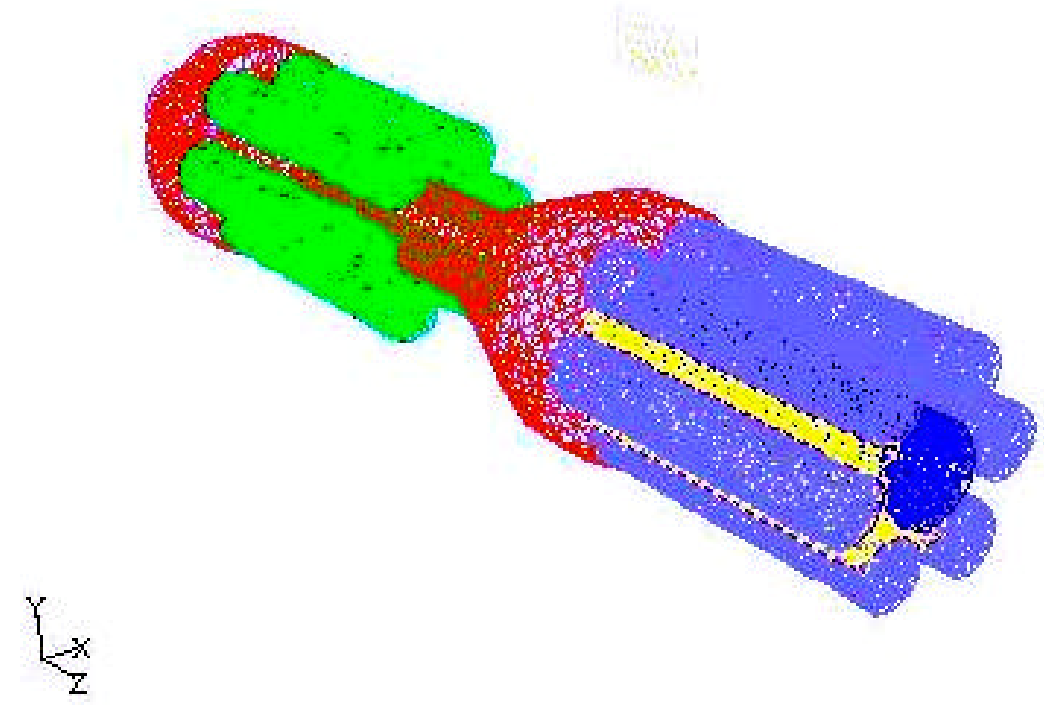

Figure 23. Schematic grids of the equivalent filters model and the ash bridging region.

Figure 24 shows the contour plots for variations of static pressure at a section across the lower tier filters of the PCD vessel with and without ash bridging. It is seen that in both cases the pressure remains almost constant and relatively high inside the shroud and in the main body of the vessel. In the body of the filter vessel the pressure is quite high and roughly uniform and reduces significantly as the gas passes through ceramic filter wall and enters the candle filter cavity. Figure 24 also shows that the ash bridging does not have a noticeable effect on the pressure distribution in the vessel.
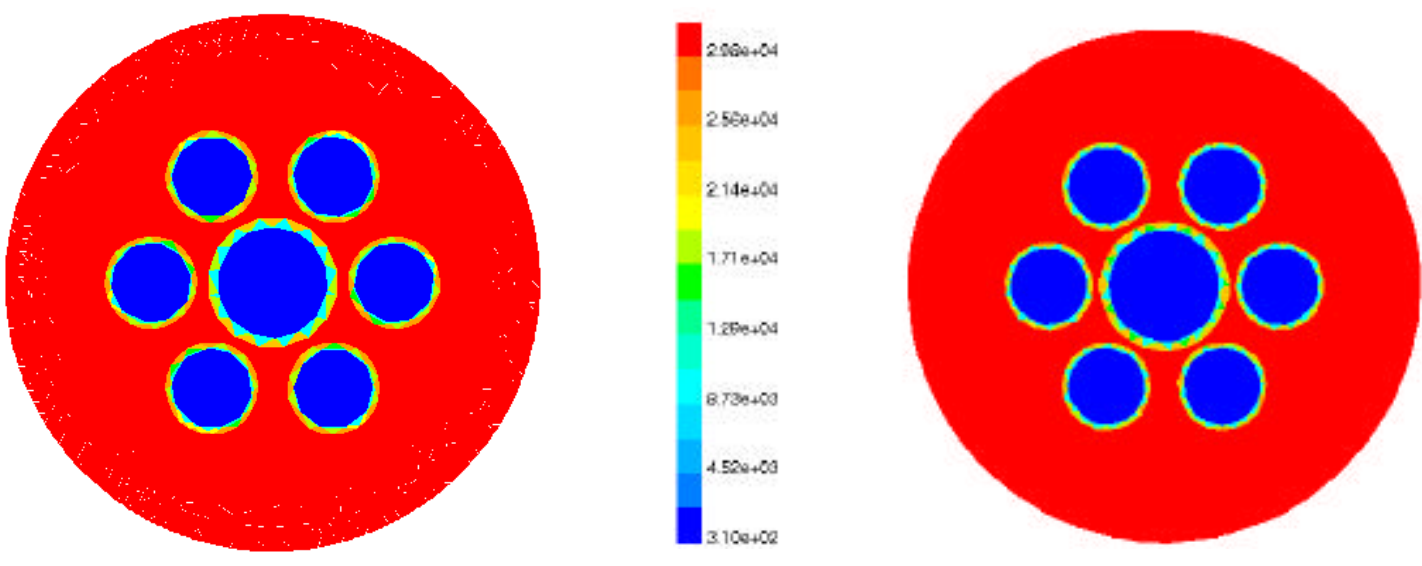


\section{a) Without Ash Bridging}

\section{b) With Ash Bridging}

Figure 24. Variation of the static pressure at the section across the lower tiers.

Variations of the temperature contours at a section across the lower filter clusters of the PCD vessel with and without ash bridging are shown in Figure 25. Figure 25a shows that in the absence of ash bridging the temperature is relatively high and roughly uniform around the filters. However, when the ash bridging occurs, Figure $25 \mathrm{~b}$ shows that the temperature in the body of the vessel decreases somewhat, but remains remain roughly uniform.

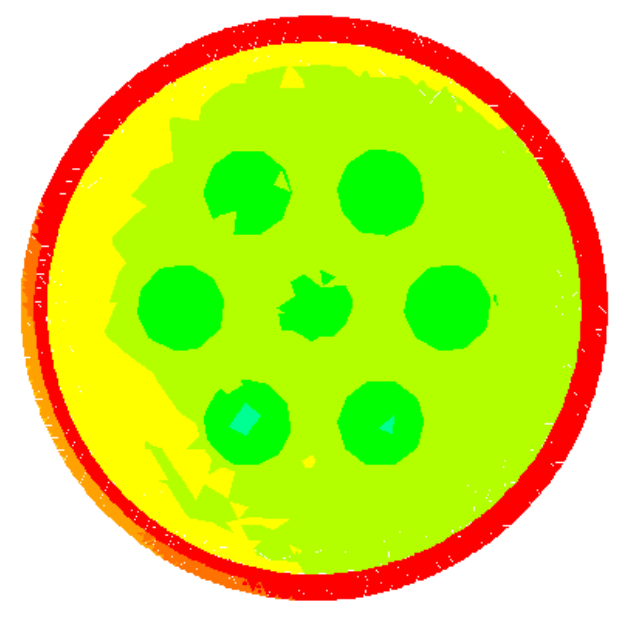

a) Without Ash Bridging

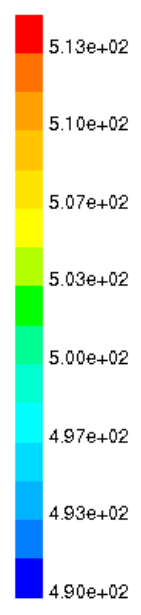

b) With Ash Bridging

Figure 25. Variations of the temperature distribution at a section across the lower tier filters. 
Figure 26 shows the variation of the temperature contours at a section across the upper filter clusters for the case that ash bridging is absent or present. It is seen that in the temperature in upper part of the filter is generally higher than that in the low part. This

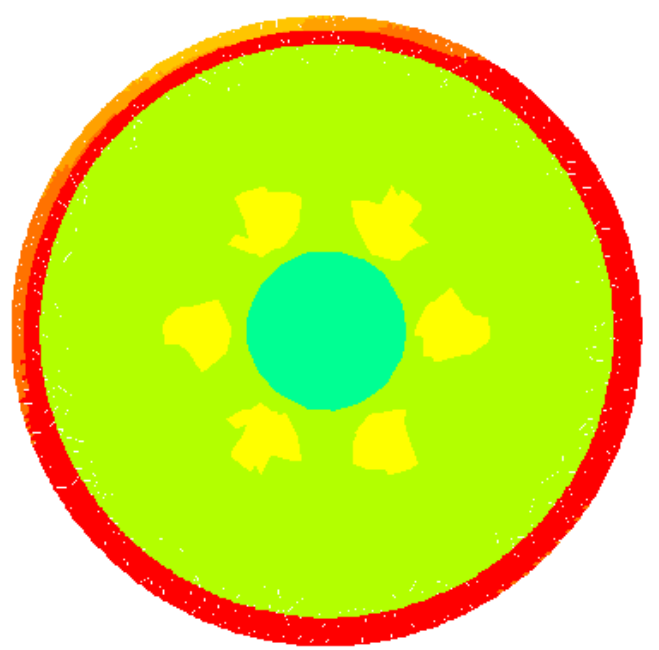

a) Without Ash Bridging

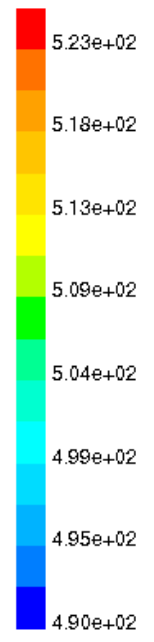

Figure 26. Variations of the temperature distribution at a section across the upper tier filters.

is because there is comparatively more surface area for heat transfer in the lower part of the filter. The temperature difference between the upper and lower filters for the case with ash bridging is higher that than in the absence of ash bridging. When ash bridging occurs in the lower tier filters, there will be more resistance to the gas flow, and the flow rate through the upper tier filters increases accordingly. This results in the slightly higher temperature in the upper region of the vessel.

\section{a) Without Ash Bridging}

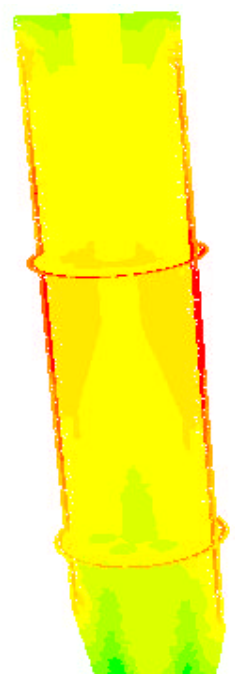

b) With Ash Bridging

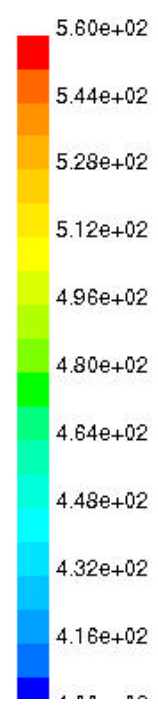


Figure 27. Variations of the temperature distribution at a section across the filter vessel.

Temperature variations at a section along the PCD vessel with and without ash bridging are shown in Figure 27. It is seen that that in the absence of ash bridging the temperature is more uniform along the vessel, while it becomes more nonuniform when ash bridging in the lower tier occurs.

Temperature variations in the region containing ash bridging is shown in Figure 28. Here the refine temperature scale used shows that the lower part of the ash-bridging region is about $10 \mathrm{~K}$ cooler than its top part. In addition, temperature decreases slightly to due the ash bridging in the lower tier of the filter vessel
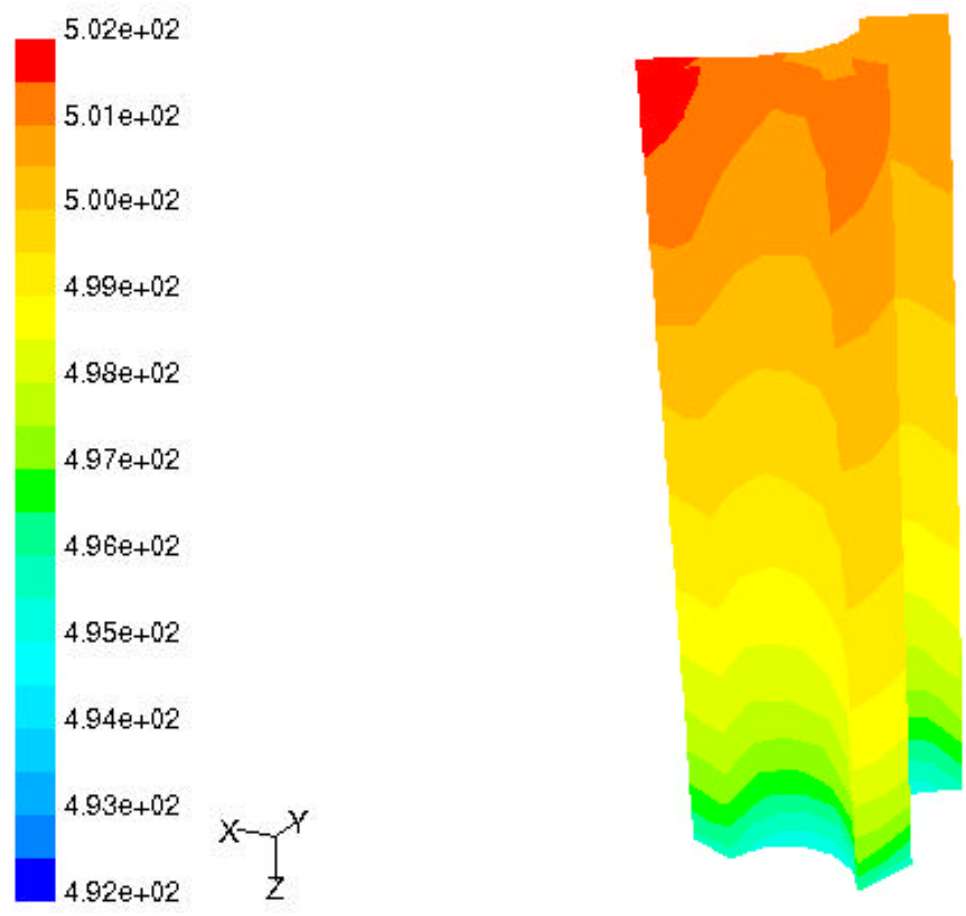

Figure 28. Variation of the temperature distribution along the ash bridging.

During the operation of the Particle Control Device (PCD) at Power System Development Facilities, temperature variations along a number of candle filters were measured (Foote, 2002). In the case that ash bridging shown in Figure 21 occurs, the corresponding measured temperature variation reported by Foote 
(2002) is shown in Figure 29. The computer simulation result is also plotted in this figure for comparison.

Here the distance is measured from the top of the candle filter. It is seen that the temperature decreases along the candle filter toward the bottom of the vessel. The temperature variation is more pronounced when ash bridging in the lower tier occurs. The presence of ash bridging leads to lower temperature in the lower region of the vessel. The computational model predictions appear to be in reasonable agreement with the measurements.

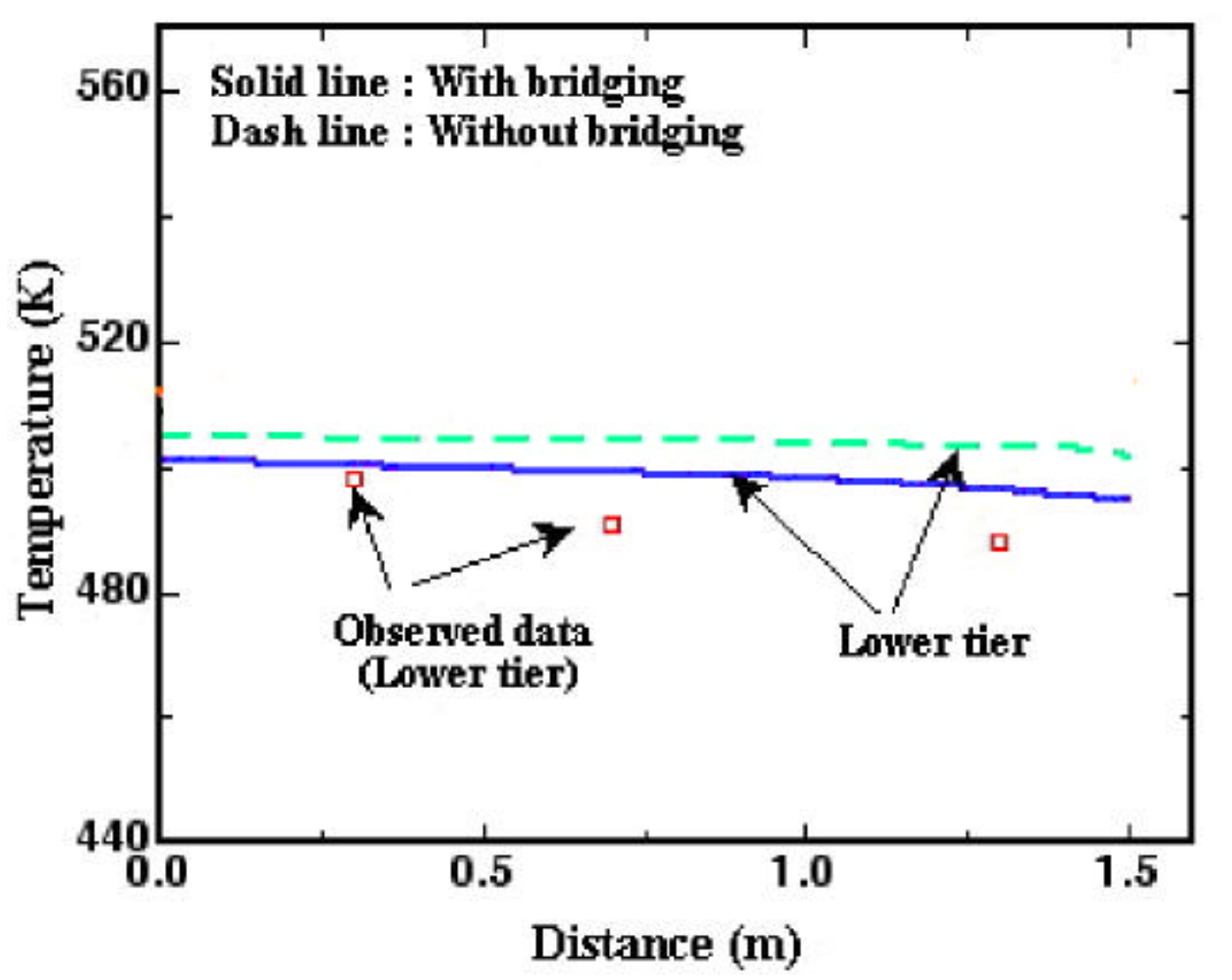

Figure 29. Comparison of the experimental and the simulation results for the temperature variation along the ash bridging region.

Figure 30 shows the variations of gas velocity magnitude at a section across the vessel with and without ash bridging. This figure shows that the velocity field in the vessels with and without ash bridging is roughly the same. A careful examination, however, indicates that the velocity in the lower part of the vessel with ash bridging is slightly lower than the case in the absence of ash bridging.

Contour plots for variations of gas velocity magnitude at a section across the lower tier filters with and 
without ash bridging are shown in Figure 31. Here a more refine scale is used. This figure shows that the velocity is rather high in the spacing between the shroud and the vessel wall. In the body of the vessel, the velocity is low is markedly reduced due to the presence of ash bridging.
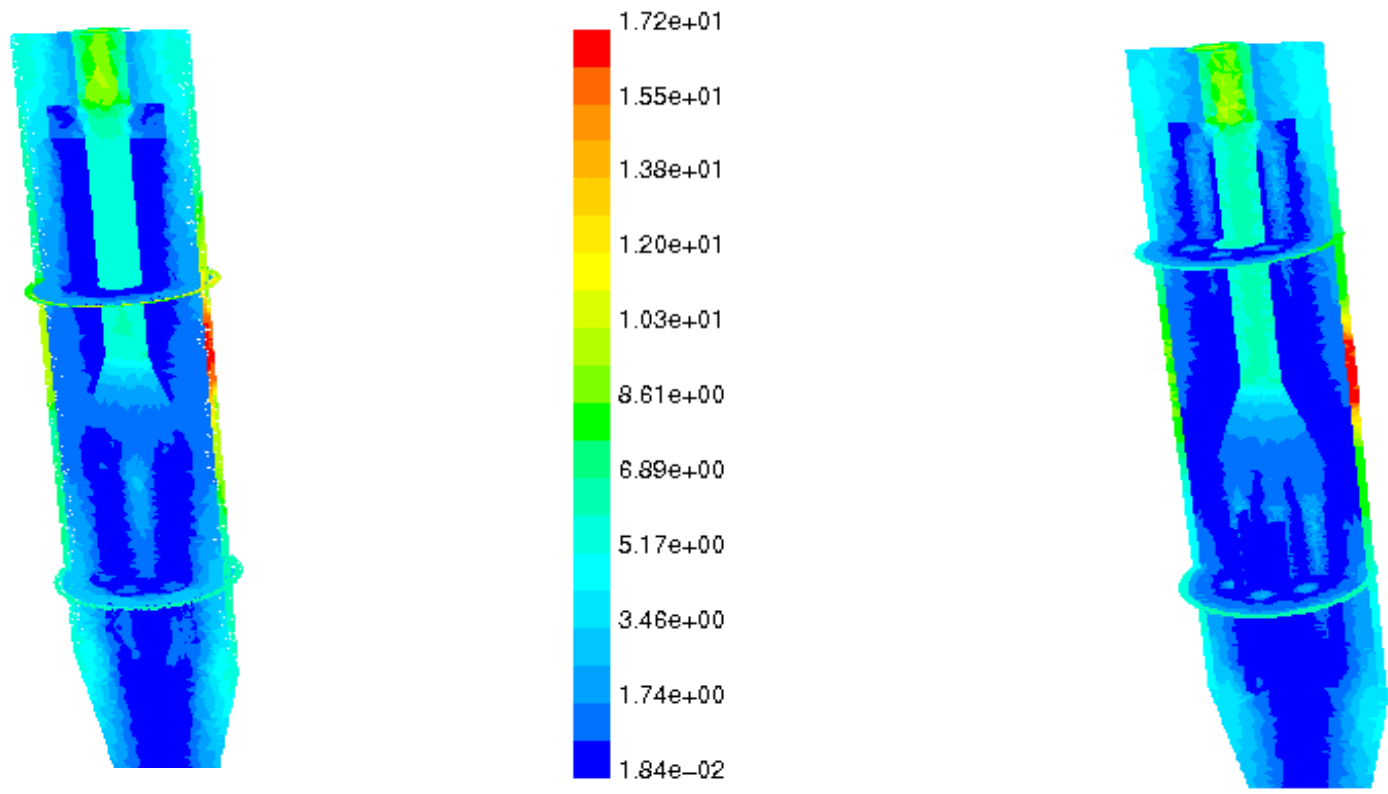

\section{a) Without Ash Bridging}

\section{b) With Ash Bridging}

Figure 30. Variations of the velocity distribution across the vessel.

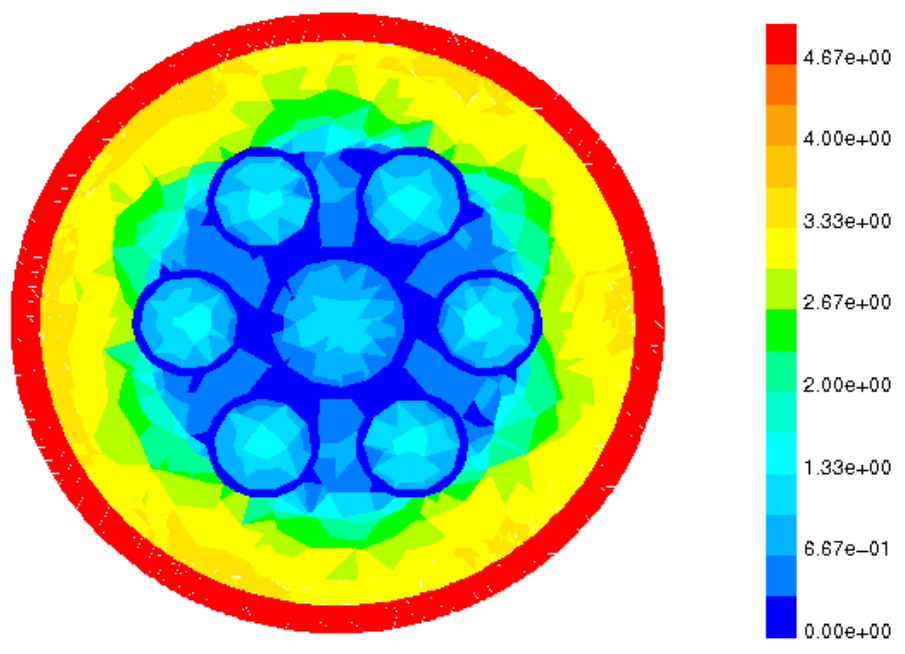

b) Without Ash Bridging

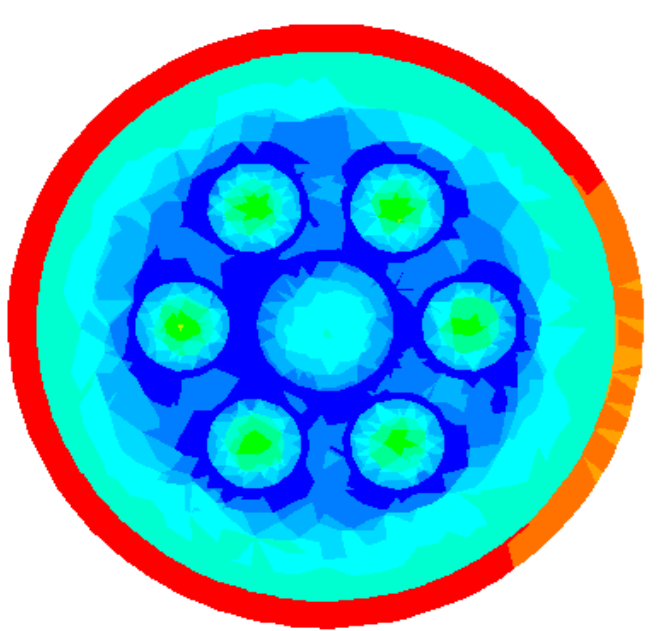

b) With Ash Bridging 
Figure 31. Variations of the velocity distribution at a section across the lower tier filters. 
Velocity vector plots at a section across the lower tier filters with and without ash bridging are shown in Figure 32. It should be emphasized the grid used for the case without ash bridging was much denser near the vessel wall and the shroud. The rotating flow pattern can be clearing seen form this figure. Careful examination of the figure shows that the presence of ash bridging reduces the velocity in the lower part of the vessel.

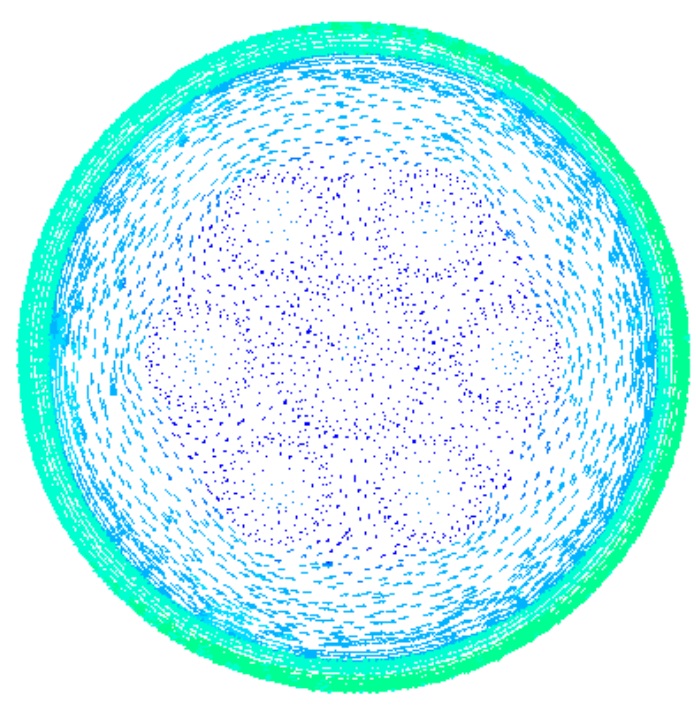

a) Without Ash Bridging

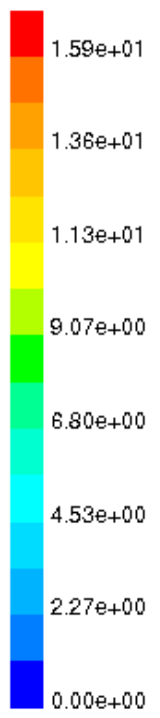

b) With Ash Bridging

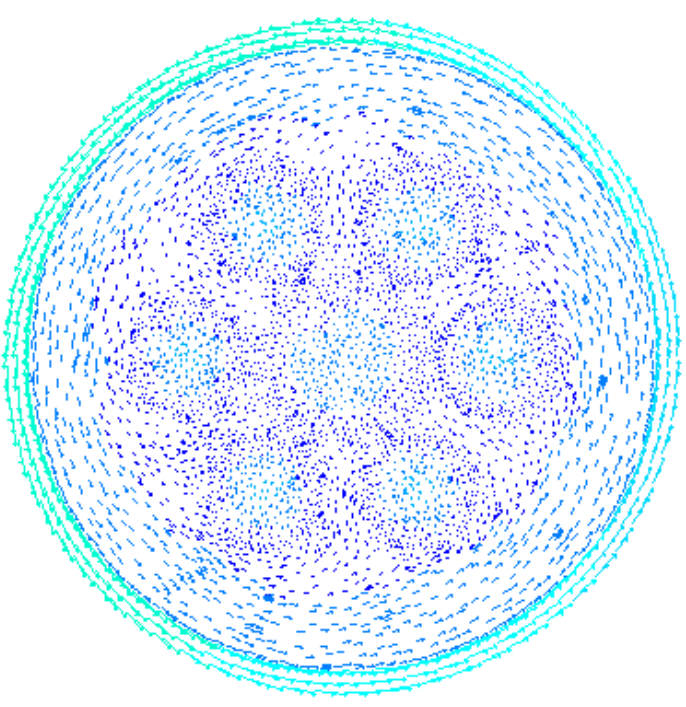

Figure 31 Variations of the velocity vector field at a section across the lower tier filters.

\section{Conclusions}

In this section, effects of ash bridging on the temperature distribution in the Seimens-Westinghouse filter vessel at Power Development Facility in Wilsonville, Alabama are studied. The Reynolds stress turbulent model of FLUENT ${ }^{\mathrm{TM}}$ code is used and the gas mean velocity and temperature distribution in the filter vessel are evaluated. On the basis on the presented results, the following conclusions are drawn: 
- The presence of ash bridging in the lower tier filters reduces the gas velocity magnitude in the lower region of the filter vessel.

- Temperature reduces in the lower part of the vessel due to ash bridging.

- Temperature distribution is somewhat nonuniform in the filter vessel with upper part being somewhat hotter than the lower part.

- The presence of ash bridging increases the temperature variation in the vessel.

- Temperature decreases along the ash bridging region from top to bottom and there is about $10 \mathrm{~K}$ temperature difference along this region.

\section{References}

Foote, J. (2002), Private Communication.

Zhang, H. and Ahmadi, G. (2001) Particles Transport and Deposition in the Hot-Gas Filter Vessel at Wilsonville, Powder Technology, Vol. 116, pp. 53-68. 


\section{STUDENTS AND COLLABORATORS}

A number of graduate students including five Ph.D. and two MS students were involved with various stages of this research project. Three of these students were graduated and are currently working at Corning Exxon and Asyst Technologies. In addition several undergraduate students benefited from this research. The graduate students associated with this project were:

- P. Zamankhan, graduate (Ph.D) student, Department of Mechanical and Aeronautical Engineering, Clarkson University

- A.R. Mazaheri, graduate (Ph.D) student, Department of Mechanical and Aeronautical Engineering, Clarkson University

- C. Liu, graduate (Ph.D) student, Department of Mechanical and Aeronautical Engineering, Clarkson University

- T. White, graduate (MS) student, Department of Mechanical and Aeronautical Engineering, Clarkson University

- C. Toscano, graduate (MS) student, Department of Mechanical and Aeronautical Engineering, Clarkson University (Currently with EXXON)

- C. He, graduate (Ph.D) student, Department of Mechanical and Aeronautical Engineering, Clarkson University (Currently with Corning)

- H. Zhang, graduate (Ph.D) student, Department of Mechanical and Aeronautical Engineering, Clarkson University (Currently with Asyst Technology) 


\section{PUBLICATION AND PRESENTATIONS}

\section{Journals Articles (peer reviewed)}

Soltani, M., Ounis H., Ahmadi, G. and McLaughlin, J.B. Direct Numerical Simulation of Charged Particle Deposition in a Turbulent Flow, Int. J. Multiphase Flow, Vol. 24, pp. 77-94, (1988).

Smith, D.H., Powell, V. and Ahmadi, G. Analysis of Operational Filtration Data, Part II. Incomplete Cleaning of Candle Filters, Powder Technology, Vol. 97, pp. 139-145 (1998).

Elliott, K.E., Ahmadi, G. and Kvasnak, W., Couette Flows of Granular Monolayer - An Experimental Study, J. Non-Newtonian Fluid Mechanics, Vol. 74, pp. 89-111 (1998).

Ahmadi, G. and Smith, D.H., Particle Transport and Deposition in a Hot-Gas Cleanup Pilot Plant, Aerosol Science and Technology, Vol. 29, pp. 183-205 (1998).

Ahmadi, G. and Smith, D.H., Gas Flow and Particle Deposition in the Hot-Gas Filter Vessel at the Tidd 70 MWE PFBC Demonstration Plant, Aerosol Science and Technology, Vol. 29, pp. 206-223 (1998).

Smith, D.H., Powell, V. Ahmadi, G. and M. Ferer, Analysis of Operational Filtration Data, Part III. Re-entrainment and Incomplete Cleaning of Dust Cake, Aerosol Science and Technology, Vol. 29, pp. 224-235, (1998).

Smith, D.H. and Ahmadi, G., Problem and Progress in Hot-Gas Filtration for Pressurized Fluidized Bed Combustor (PFBC) and Integrated Gasification Combined Cycle (IGCC), Aerosol Science and Technology, Vol. 29, pp. 163-169 (1998).

He, C. and Ahmadi, G., Particle Deposition with Thermophoresis in Laminar and Turbulent Duct Flows, Aerosol Science and Technology, Vol. 29, pp. 525-546 (1998).

Ahmadi, G. and Chen, Q., Dispersion and Deposition of Particles in a Turbulent Pipe Flow with Sudden Expansion, J. Aerosol Science Vol. 29, pp. 1097-1116 (1998).

He, C. and Ahmadi, G., Particle Deposition in a Nearly Developed Turbulent Duct Flow with Electrophoresis, J. Aerosol Science, Vol. 30, pp. $739-758$ (1999).

Soltani, M. and Ahmadi, G., Detachment of Rough Particles with Electrostatic Attraction From Surfaces in Turbulent Flows, J. Adhesion Sci. Technol., Vol. 13, pp. 325-355 (1999).

Soltani, M. and Ahmadi, G., Charged Particle Trajectory Statistics and Deposition in a Turbulent Channel Flow, Aerosol Science Technology, Vol. 31, pp. 170-186 (1999). 
Ahmadi, G. and Li, A., Computer Simulation of Particle Transport and Deposition Near a Small Isolated Building, J. Wind Energy Industrial Aerodynamics, Vol. 84, pp. 23-46 (2000).

Soltani, M., Ahmadi, G. and Hart, S. C., Electrostatic Effects on Resuspension of Rigid-Link Fibers in Turbulent Flows, Colloids Surfaces, Vol. 165, pp. 189-208 (2000).

Zhang, H. and Ahmadi, G., Aerosol Particle Transport and Deposition in Vertical and Horizontal Turbulent Duct Flows, J. Fluid Mechanics, Vol. 406, pp. 55-80 (2000).

Fan, F.G. and Ahmadi, G., Wall Deposition of Small Ellipsoids From Turbulent Air Flows - A Brownian Dynamics Simulation, J. Aerosol Science Vol. 31, pp. 1205-1229 (2000).

Cao, J. and Ahmadi, G., Gas-Particle Two-Phase Flow in Horizontal and Inclined Ducts, Int. J. Engineering Science, Vol. 38, pp. 1961-1981 (2000).

Soltani, M. and Ahmadi, G., Direct Numerical Simulation of Curly Fibers in Turbulent Channel Flow, Aerosol Science Technology, Vol. 33, pp. 392-418 (2000).

Ahmadi, G., He, C., Ban, H. and Stencel, J.M., Air Flow and Particle Transport in Triboelectric Coal/Ash Cleaning System-Counter Flowing Straight Duct Design, Particulate Science Technology, Vol. 18, pp. 213-256 (2000).

Shams, M., Ahmadi, G. and Rahimzadeh, H., A Sublayer Model for Deposition of Nano- and Micro-Particles in Turbulent Flows, Chemical Engineering Science, Vol. 55, pp. 6097-6107 (2000).

Zhang, H. and Ahmadi, G., Aerosol Particle Removal and Re-entrainment in Turbulent Flows- A Direct Numerical Simulation Approach, J. Adhesion, Vol. 74, pp. $441-493$ (2000).

Zhang, H., Ahmadi, G., Fan, F.-G. and McLaughlin, J.B., Ellipsoidal Particles Transport and Deposition in Turbulent Channel Flows, International Journal Multiphase Flows, Vol. 27, pp. 971-1009 (2001).

Zhang, H. and Ahmadi, G., Particles Transport and Deposition in the Hot-Gas Filter Vessel at Wilsonville, Powder Technology, Vol. 116, pp. 53-68 (2001).

Shams, M., Ahmadi, G. and Rahimzadeh, H., Transport and Deposition of Flexible fibers in Turbulent Duct Flows, Journal of Aerosol Science, Vol. 32, pp. 525-547 (2001).

Ahmadi, G. and C. He, Simulation of Particles Transport and Deposition in a Combustor, Chemical Engineering Communication, Vol. 187, pp. 23-53 (2001).

Mansoori, Z., Saffar-Avval, M., Basirat Tabrizi, H and Ahmadi, G., Modeling of Heat Transfer in Turbulent Gas-Solid Flow, International Journal Heat Mass and Transfer, Vol. 45, pp. 1173-1184 (2002). 


\section{Conference Presentations}

G. Ahmadi, "Recent Advances in Computational Modeling of Particle Transport and Deposition in Hot-Gas Cleanup Filter Vessels," Symposium on High-Temperature Particulate Cleanup for Advanced Coal-Based Power Systems, FETC-DOE/EPRI Birmingham, AL, April 20-23, 1998.

G. Ahmadi and X. Xia, "Numerical Simulation of Helical Particle Transport in Turbulent Flows," The 1998 Annual Technical Meeting of the Center for Advanced Material Processing (CAMP), Lake Placid, NY, May 20-22, 1998.

G. Ahmadi, M. Soltani and J.B. McLaughlin, "Effect of Near Wall Flow Structures on Deposition of Charged Particles in Turbulent Channel Flows," Third International Conference on Multiphase Flows, ICMF' 98, Lyon, France, June 8-12, 1998.

G. Ahmadi, H. Zhang and F.G. Fan, "Ellipsoidal Particle Transport and Deposition in Turbulent Channel Flows," Third International Conference on Multiphase Flows, ICMF 98, Lyon, France, June 8-12, 1998.

G. Ahmadi and D.H. Smith, "Particle Transport and Deposition in the IGCF Hot-Gas Cleanup Filter Vessel," Third International Conference on Multiphase Flows, ICMF 98, Lyon, France, June 8-12, 1998.

J.C. Gayne and G. Ahmadi, "Experimental Study of Deposition and Transport of Glass Particles and Fibers," 17th Annual Conference of the American Association for Aerosol Research, AAAR '98, Cincinnat, OH, June 22-26, 1998.

C. He and G. Ahmadi, "Particle Deposition with Electrical and Magnetic Effects in a Nearly Developed Turbulent Duct Flow," 17th Annual Conference of the American Association for Aerosol Research, AAAR '98, Cincinnati, OH, June 22-26, 1998.

S. Guo and G. Ahmadi, "Effects of Electrostatic and Capillary Forces on Bumpy Particle Adhesion and Removal," 17th Annual Conference of the American Association for Aerosol Research, AAAR '98, Cincinnat, OH, June 22-26, 1998.

H. Zhang and G. Ahmadi, "Particle Deposition in Turbulent Duct Flows in the Presence of Gravity," 17th Annual Conference of the American Association for Aerosol Research, AAAR '98, Cincinnati, OH, June 22-26, 1998.

B. Asgharian and G. Ahmadi, "The effect of Fiber Geometry on Fiber Deposition in Small Airways of the Lung," 17th Annual Conference of the American Association for Aerosol Research, AAAR '98, Cincinnati, OH, June 22-26, 1998. 
G. Ahmadi, H. Zhang, F.G. Fan and J.B. McLaughlin "Fiber Transport and Deposition in Turbulent Flows," 17th Annual Conference of the American Association for Aerosol Research, AAAR 98, Cincinnati, OH, June 22-26, 1998.

D.J. Schmidt and G. Ahmadi, "Particle Transport in Two-Dimensional Bernard Convection," 17th Annual Conference of the American Association for Aerosol Research, AAAR '98, Cincinnati, OH, June 22-26, 1998.

F.G. Fan and G. Ahmadi, "Brownian Dynamics Simulation of Spherical and Elongated Particles in a Near-Wall Vortical Flow - Turbulent Deposition Process," 1998 ASME Fluid Engineering Division Summer Meeting, Washington, DC, June 21-25, 1998, FEDSM-5026.

C. He and G. Ahmadi, "Charged Particle Deposition in a Short Vertical Duct, "1998 ASME Fluid Engineering Division Summer Meeting, Washington, DC, June 21-25, 1998, FEDSM-5025.

D.J. Schmidt and G. Ahmadi, "The Motion of Spherical Particles in Two-Dimensional Bernard Convection," 51st Annual Meeting of American Physical Society, Division of Fluid Dynamics, Philadelphia, PA, November 22-24, 1998.

H. Zhang and G. Ahmadi, "On Aerosol Particle Removal, Resuspension and Re-entrainment in Turbulent Channel Flows," 51st Annual Meeting of American Physical Society, Division of Fluid Dynamics, Philadelphia, PA, November 22-24, 1998.

C. He and G. Ahmadi, "Simulation of Particle Dispersion and Deposition with Thermophoresis in Duct Flows and in a Combustor," 51st Annual Meeting of American Physical Society, Division of Fluid Dynamics, Philadelphia, PA, November 22-24, 1998.

T. K. White and G. Ahmadi, AParticle Transport and Deposition in Hot-Gas Cleanup Filter Vessels, @lhe First Annual Symposium on Undergraduate Research Experiences (SURE) at Clarkson University, April 17, 1999.

G. Ahmadi, Ferer, M. and Smith, D.H., Aroblem and Progress in Hot-Gas Filtration for Pressurized Fluidized Bed Combustor (PFBC) and Integrated Gasification Combined Cycle (IGCC),@rhe 1999 Annual Technical Meeting of the Center for Advanced Material Processing (CAMP), Lake Placid, NY, May 19-21, 1999.

H. Zhang and G. Ahmadi, "Particle Transport, Deposition in the Hot Gas Filter Vessel at Wilsonville, @lhe 1999 Annual Technical Meeting of the Center for Advanced Material Processing (CAMP), Lake Placid, NY, May 19-21, 1999.

C. He and G. Ahmadi, AParticle Transport and Deposition with Thermophoresis in a Reactor,@rhe 1999 Annual Technical Meeting of the Center for Advanced Material Processing (CAMP), Lake Placid, NY, 
May 19-21, 1999.

G. Ahmadi, AUsing Fluent in particle Transport and Deposition Research, @1999 Fluent Users=Group Meeting, Danvers, MA, May 25-27, 1999.

G. Ahmadi and J. Cao, "Anisotropic Model for Granular and Dense two-Phase Flows," 1999 ASME Mechanics and Materials Conference, Blacksburg, VA, June 27-30, 1999.

G. Ahmadi, K. Elliott and W. Kvasnak, "An Experimental Study of Granular Flow in a Couette Flow Device," 1999 ASME Mechanics and Materials Conference, Blacksburg, VA, June 27-30, 1999.

M. Shams and G. Ahmadi, Aransport and Deposition of Flexible Fibers in Turbulent Sublayer,@1 8th Annual Conference of the American Association for Aerosol Research, AAAR '99, Tacoma. WA, October $11-15,1999$.

M. Soltani and G. Ahmadi, ATransport and Deposition of Curly Fibers in Turbulent Flow,@8th Annual Conference of the American Association for Aerosol Research, AAAR '99, Tacoma. WA, October 11-15, 1999.

C. He and G. Ahmadi, "Modeling of Particle Dispersion and Deposition with Thermophoresis in a Controlled Profile Combustor," 18th Annual Conference of the American Association for Aerosol Research, AAAR '99, Tacoma. WA, October 11-15, 1999.

D. J. Schmidt and G. Ahmadi, "Dispersion of Particle in a Spray Chamber," 18th Annual Conference of the American Association for Aerosol Research, AAAR '99, Tacoma. WA, October 11-15, 1999.

H. Zhang and G. Ahmadi, "Aerosol Particle Removal and Re-entrainment in Turbulent Channel Flows," 18th Annual Conference of the American Association for Aerosol Research, AAAR '99, Tacoma. WA, October 11-15, 1999.

D. Cole, G. Ahmadi, M. Glauser and W. Kvasnak, An Experimental and Numerical Study of Turbulent Flow in an Axisymmetric Sudden Expansion" 52st Annual Meeting of American Physical Society, Division of Fluid Dynamics, New Orleans, LA, November 21-23, 1999.

D.J. Schmidt and G. Ahmadi, "Droplet Dispersion in a Spray Chamber," 52st Annual Meeting of American Physical Society, Division of Fluid Dynamics, New Orleans, LA, November 21-23, 1999.

H. Zhang and G. Ahmadi, F. Fan and J.B. McLaughlin, "Analysis of the Motion of Ellipsoidal Particle in Turbulent Channel Flows," 52st Annual Meeting of American Physical Society, Division of Fluid Dynamics, New Orleans, LA, November 21-23, 1999.

M. Shams, G. Ahmadi and H. Rahimzadeh, ATransport and Deposition of Flexible Fibers in Turbulent 
Flows, @2st Annual Meeting of American Physical Society, Division of Fluid Dynamics, New Orleans, LA, November 21-23, 1999.

G. Ahmadi and H. Zhang, "Gas Flow and Particle Transport and Deposition in the Hot Gas Filter Vessel at Wilsonville, @2st Annual Meeting of American Physical Society, Division of Fluid Dynamics, New Orleans, LA, November 21-23, 1999.

G. Ahmadi, "Industrial Application of Particle Transport, Deposition, and Removal," Annual Technical Meeting of the Center for Advanced Material Processing (CAMP), Lake Placid, NY, May 23-25, 2000.

M. Shams and G. Ahmadi, "Experimental and Mathematical Modeling of Aerosol Deposition in Turbulent Duct Flows," Annual Technical Meeting of the Center for Advanced Material Processing (CAMP), Lake Placid, NY, May 23-25, 2000.

P.V. Skudarnov, L.L. Regel, W. R. Wilcox and G. Ahmadi, "Numerical Modeling and Flow Visualization in the Gradient Freeze Configuration During Centrifugation," Fourth International Workshop on Materials Processing at High Gravity, Clarkson University, Potsdam, NY, May 29-June 2, 2000.

A.R. Mazaheri, H. Zhang and G. Ahmadi, "a Centrifual Filtration Concept for Hot-Gas Cleaning," Fourth International Workshop on Materials Processing at High Gravity, Clarkson University, Potsdam, NY, May 29-June 2, 2000.

G. Ahmadi and H. Zhang, "Resuspension of Particles in Turbulent Flows," Seventh International Symposium on Particles on Surfaces: Detection, Adhesion and Removal, Newark, NJ, June 19-21, 2000.

G. Ahmadi and D.H. Smith, "Analysis of Backpulse Process for a Hot-Gas Filter Vessel," Seventeenth Annual International Pittsburgh Coal Conference, Pittsburgh, PA, September 11-14, 2000.

G. Ahmadi and D.H. Smith, "Particle Deposition in the Pinon Pine Filter Vessel," Seventeenth Annual International Pittsburgh Coal Conference, Pittsburgh, PA, September 11-14, 2000.

G. Ahmadi and H. Zhang, "Hot-Gas Flow and Particle Transport and Deposition in the Filter Vessel at Wilsonville," Seventeenth Annual International Pittsburgh Coal Conference, Pittsburgh, PA, September 11-14, 2000.

A.R. Mazaheri and G. Ahmadi, "Computational Modeling of a Centrifual Filtration System," 19th Annual Conference of the American Association for Aerosol Research, AAAR 2000, St. Louis, MO, November 6-10, 2000.

D.J. Schmidt, G. Ahmadi, and G. Schmidt, "Dispersion of Droplets in a Turbulent Spray," 19th Annual Conference of the American Association for Aerosol Research, AAAR 2000, St. Louis, MO, November 6-10, 2000. 
C. Liu and G. Ahmadi, "Atmospheric Particle Transport and Deposition Near a Building Model," 19th Annual Conference of the American Association for Aerosol Research, AAAR 2000, St. Louis, MO, November 6-10, 2000.

H. Zhang and G. Ahmadi, "Analysis of Particle Transport and Deposition in the Hot-Gas Filter Vessel," 19th Annual Conference of the American Association for Aerosol Research, AAAR 2000, St. Louis, MO, November 6-10, 2000.

M. Shams, G. Ahmadi and H. Rahimzadeh, "Transport and Deposition of Flexible Fibers in Turbulent Flows," 19th Annual Conference of the American Association for Aerosol Research, AAAR 2000, St. Louis, MO, November 6-10, 2000.

H. Zhang, G. Ahmadi, R. Han and B.J. Greenspan, "Impact Breakup of Particle Pairs," 19th Annual Conference of the American Association for Aerosol Research, AAAR 2000, St. Louis, MO, November 6-10, 2000.

H. Zhang, G. Ahmadi, R. Han and B.J. Greenspan, "Breakup of Pairs of Attached Particles in Simple Shear Flows," 19th Annual Conference of the American Association for Aerosol Research, AAAR 2000, St. Louis, MO, November 6-10, 2000.

D.J. Schmidt, G. Ahmadi, and G. Schmidt, "Lagrangian PDF: Application to Multiphase Spray Simulation," 4th International Conference on Multiphase Flows, ICMF' 2001, New Orleans, LA, May 27-June 1, 2001.

C. Liu and G. Ahmadi, "Transport and Deposition of Atmospheric Particles Near a Building Model," 4th International Conference on Multiphase Flows, ICMF 2001, New Orleans, LA, May 27-June 1, 2001.

M. Shams, G. Ahmadi and H. Rahimzadeh, "Flexible Fiber Motion in Turbulent Flows," 4th International Conference on Multiphase Flows, ICMF 2001, New Orleans, LA, May 27-June 1, 2001.

A. Sadiki and G. Ahmadi, "A Thermodynamical Formulation for Chemically Active Multiphase Flows," Trends in Numerical and Physical Modeling for Industrial Multiphase Flows, Institut d'Etudes Scientifiques de Cargese (Corse), France. September 26-28, 2001.

A.R. Mazaheri and G. Ahmadi, "Computational Modeling of Gas Flow in an Industrial Filter Vessel," 20th Annual Conference of the American Association for Aerosol Research, AAAR 2001, Portland, Oregon, October 15-19, 2001.

A.R. Mazaheri and G. Ahmadi, "Particle Transport, Deposition and Removal with Bounce in Turbulent Channel Flow," 20th Annual Conference of the American Association for Aerosol Research, AAAR 2001, Portland, Oregon, October 15-19, 2001. 
X. Zhang and G. Ahmadi, "Gas-Particle Two-Phase Flow in a Horizontal Channel," 20th Annual Conference of the American Association for Aerosol Research, AAAR 2001, Portland, Oregon, October 15-19, 2001.

C. He, and G. Ahmadi, "Particle Dispersion and Deposition in a Sudden Expansion Turbulent Pipe Flow with Electrophoresis,"20th Annual Conference of the American Association for Aerosol Research, AAAR 2001, Portland, Oregon, October 15-19, 2001.

G. Ahmadi, "Computational Modeling of Particle Transport and Deposition," Symposium on Indoor and Urban Environmental Systems, Syracuse University, Syracuse, New York, October 30-31, 2001.

G. Ahmadi and H. Zhang, "Particle Entrainment in Turbulent Flows," $25^{\text {th }}$ Annual Meeting of Adhesion Society and the Second Word Congress on Adhesion and Related Phenomena (WCARP-II), Orlando, FL, February 10-14, 2002.

G. Ahmadi and S. Guo, "Adhesion and Detachment of Bumpy Particle In Turbulent Flows - Effects of Electrostatic and Capillary Forces," 25th Annual Meeting of Adhesion Society and the Second Word Congress on Adhesion and Related Phenomena (WCARP-II), Orlando, FL, February 10-14, 2002. 